Key Words:

Antifoam

KTPB

STTP

Retention:

Permanent

\title{
FATE OF IIT B52 ANTIFOAM AGENT ACROSS THE SMALL TANK TETRAPHENYLBORATE PROCESS
}

\author{
T. B. Calloway \\ M. A. Baich \\ D. P. Lambert
}

MARCH 31, 2001

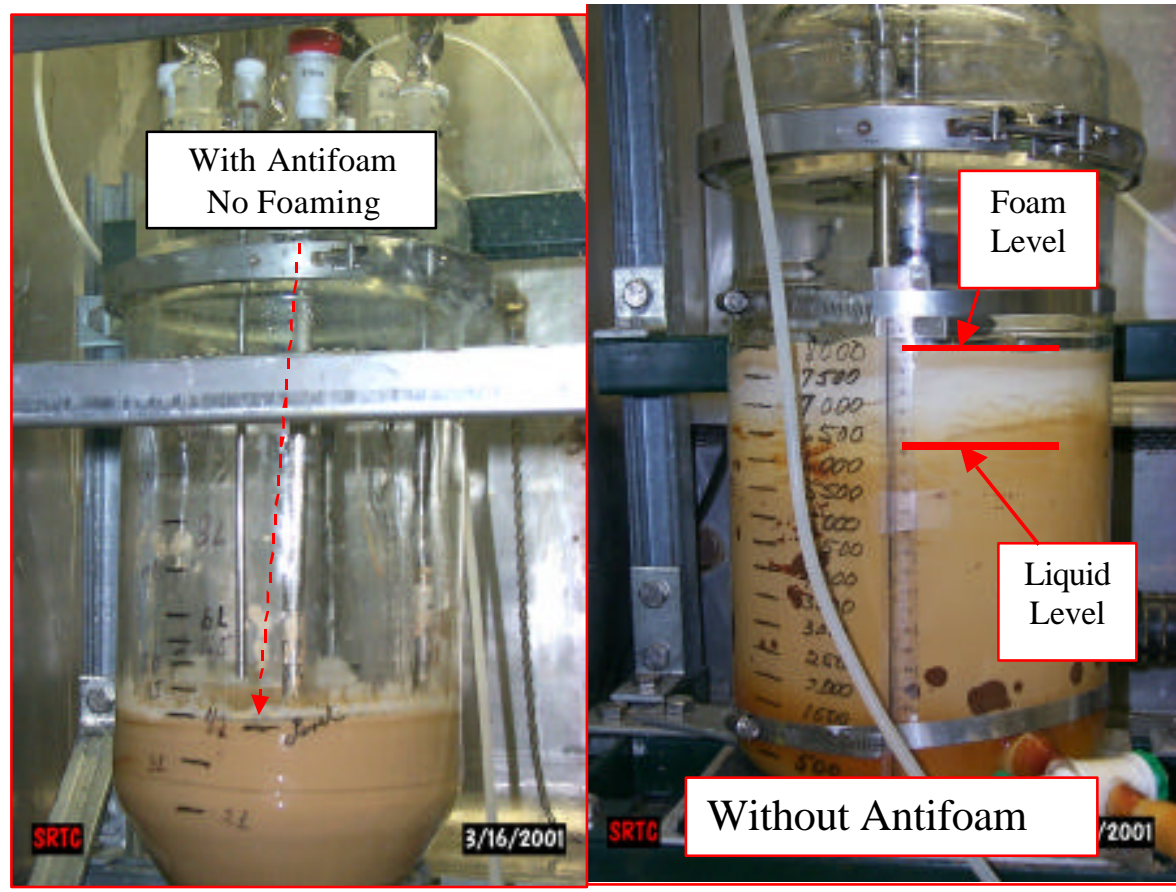

Westinghouse Savannah River Company

Savannah River Site

Aiken, SC 29808

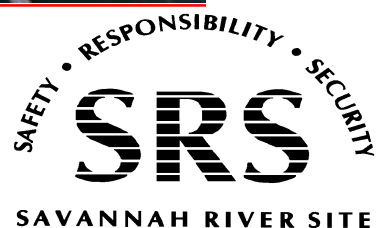

Prepared for the U.S. Department of Energy Under

Contract Number DE-AC09-96SR18500 
This document was prepared in conjunction with work accomplished under Contract No.

DE-AC09-96SR18500 with the U.S. Department of Energy.

\section{DISCLAIMER}

This report was prepared as an account of work sponsored by an agency of the United States Government. Neither the United States Government nor any agency thereof, nor any of their employees, makes any warranty, express or implied, or assumes any legal liability or responsibility for the accuracy, completeness, or usefulness of any information, apparatus, product or process disclosed, or represents that its use would not infringe privately owned rights. Reference herein to any specific commercial product, process or service by trade name, trademark, manufacturer, or otherwise does not necessarily constitute or imply its endorsement, recommendation, or favoring by the United States Government or any agency

thereof. The views and opinions of authors expressed herein do not necessarily state or reflect those of the United States Government or any agency thereof.

This report has been reproduced directly from the best available copy.

Available for sale to the public, in paper, from: U.S. Department of Commerce, National Technical Information Service, 5285 Port Royal Road, Springfield, VA 22161, phone: (800)

553-6847, fax: (703) 605-6900, email: orders@ntis.fedworld.gov online ordering: http://www.ntis.gov/ordering.htm

Available electronically at http://www.doe.gov/bridge

Available for a processing fee to U.S. Department of Energy and its contractors, in paper, from: U.S. Department of Energy, Office of Scientific and Technical Information, P.O. Box 62, Oak Ridge, TN 37831-0062, phone: (865 ) 576-8401, fax: (865) 576-5728, email: reports@ adonis.osti.gov 
Key Words:

Antifoam

KTPB

STTP

Retention:

Permanent

\title{
FATE OF IIT B52 ANTIFOAM AGENT ACROSS THE SMALL TANK TPB PROCESS
}

\author{
T. B. Calloway \\ M. A. Baich \\ D. P. Lambert
}

MARCH 31, 2001

Westinghouse Savannah River Company

Savannah River Site

Aiken, SC 29808

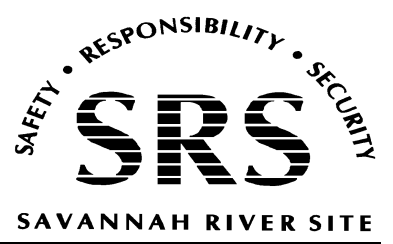

Prepared for the U.S. Department of Energy Under

Contract Number DE-AC09-96SR18500 
REVIEWS AND APPROVALS

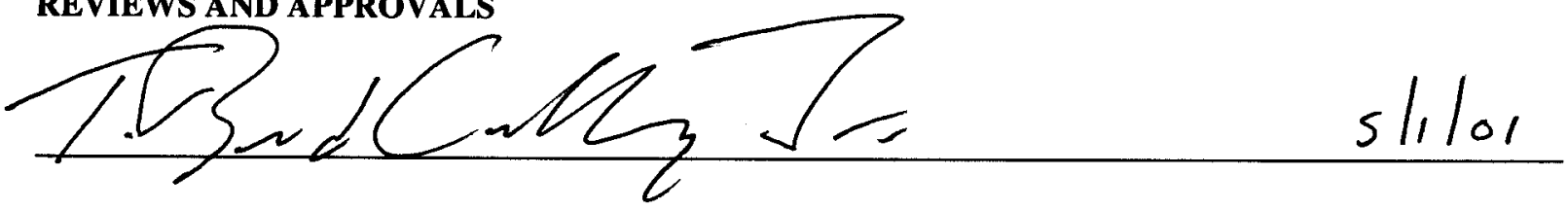

T. B. Calloway, Co-Author, Immobilization Technology

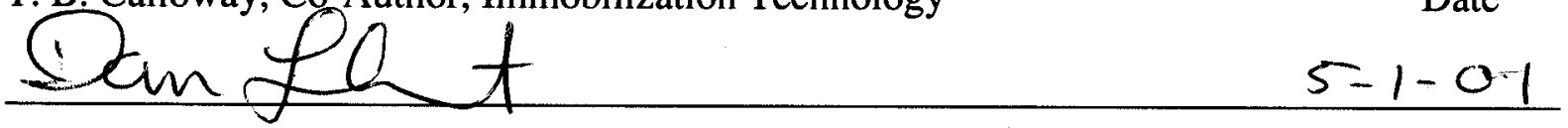

D. P. Lambert, Co-Author, Immobilization Technology

man Baich 5-2-01

M. A. Baich, Co-Author, Immobilization Technology Date

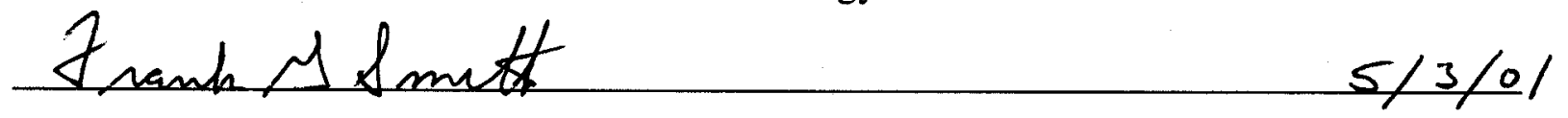

F. G. Smith, Peer Reviewer, Immobilization Technology Date

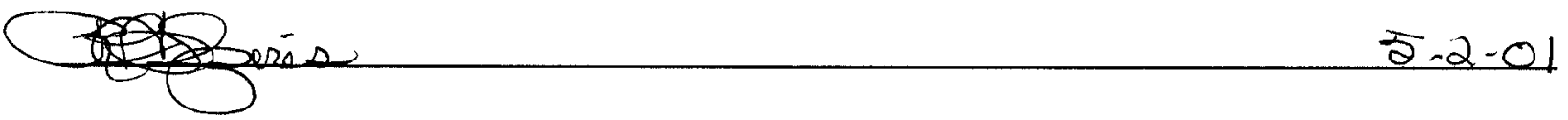

R. H. Spires, Manager, Immobilization Technology Date

f 1 luts $5 / 6 / \%$

J. T. Carter, Director of Salt Disposition Engineering

D2/mozactss

W. L. Tamosaitis, Managey Waste Processing Technology 


\section{TABLE OF CONTENTS}

LIST OF figures ................................................................................................................................................ iii

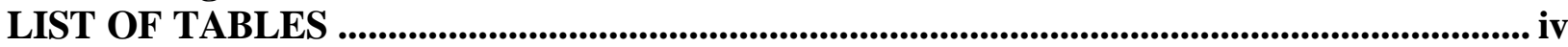

LIST OF ACRONYMS ......................................................................................................... iv

1.0 EXECUTIVE SUMMARY................................................................................................... 1

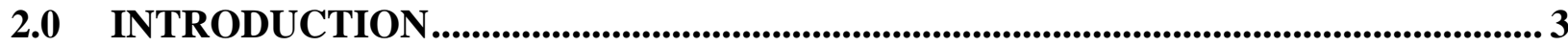

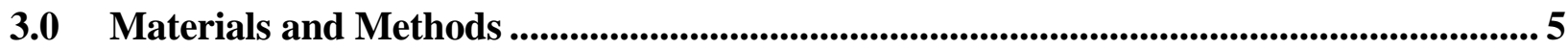

3.1 Composition of Salt Solution Simulants. ...................................................................5

3.2 Composition of IIT B52 Antifoam................................................................................. 6

3.3 Experimental Equipment ...................................................................................................... 7

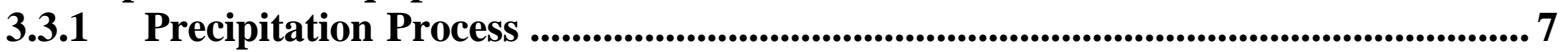

3.3.2 Concentration and Washing Processes ................................................................................. 9

4.0 Description of Experiments and Results .......................................................................... 11

4.1 No antifoam baseline ............................................................................................................. 11

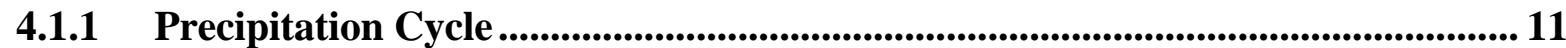

4.1.2 Concentration and Washing Cycle .................................................................................. 13

4.2 Antifoam Run with IIT B52............................................................................................... 16

4.2.1 Precipitation Cycle .................................................................................................................. 16

4.2.2 Concentration and Washing......................................................................................... 20

4.2.3 IIT B52 Sample Analysis ................................................................................................. 26

4.2.4 Insoluble Aluminum Analysis and Results .................................................................. 29

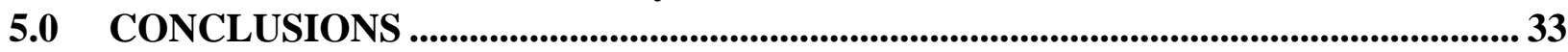

6.0 FUTURE WORK .................................................................................................................... 34

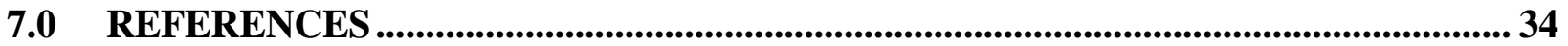

\section{LIST OF FIGURES}

Figure 1 - Simplified Process Flow Diagram for the STTP Process .......................................................................................4

Figure 2 - Schematic of CSTR Precipitation System.......................................................................................................8

Figure 3 - Schematic of Concentration and Washing Apparatus ...........................................................................................10

Figure 4 - Non Antifoam Test CSTR Precipitation Cycle Agitator at 750 rpm - Minor foam buildup during initial startup of CSTR

Figure 5 - Non Antifoam Test CSTR Precipitation Cycle - Agitator at 750 rpm after 14 days of Operation ...12 Figure 6 - Non Antifoam Baseline Test During Washing of 10 wt. \% Precipitate - Agitator Speed at 550 rpm and $1000 \mathrm{rpm}$.....................................................................................................................................................................15

Figure 7 - Precipitation Cycle No Antifoam Test - Agitator at 750 and 1000 rpm........................................................18

Figure 8 - Precipitation Cycle Antifoam Test with IIT B52 - Agitator at 1000 rpm.....................................................18

Figure 9 - Precipitation Cycle with IIT B52 Antifoam at Various Antifoam Concentration - As antifoam concentration increases, the Coalescing Action of the Antifoam Increases.................................................................19

Figure 10 - Comparison of STTP Washing Cycle With and Without Antifoam...........................................................22

Figure 11 - Comparison of Typical Precipitate Slurries Prepared With and Without IIT B52 Antifoam..........23 Figure 12 - Comparison of $4 \mathrm{wt}$. \% Precipitate Slurries after the addition of antifoam at 100 and $150 \mathrm{ppmV}$.

Figure 13 - Hydrolysis of IIT B52 (B2SS, Bis(2-ethylhexyl)sodium sulfosuccinate).......................................................28

Figure 14 - XRD Analysis of Insoluble solids in Washed Concentrated Precipitate Slurry....................................32 


\section{LIST OF TABLES}

Table 1 - Composition for 1 Liter of 4.7 M Na Salt Solution Simulant..............................................................................6

Table 2 - IIT B52 Antifoams used during Precipitation, Concentration and Washing Cycles - Note: only

Batch 2 ANAEPG used during Washing Cycle ...........................................................................................................7

Table 3 - CSTR Dimensions and Scaling Basis...........................................................................................................................................8

Table 4 - Precipitation Experimental Parameters ...........................................................................................................................9

Table 5 - IIT B52 Sample Analysis from Precipitation, Filtration and Washing........................................................26

Table 6 - Total antifoam used during the Precipitation, Concentration and Washing of Simulated Precipitate

Slurry

${ }^{\circledR}$ RA (Bis(2-ethylhexyl)sodium sulfosuccinate) at Various pH and Temperature

Conditions .27

Table 8 - 2-Ethyl-1-Hexanol (IIT B52 Hydrolysis Product) Analysis of Washed KTPB Slurry and Filtrate from Washing

Table 9 - Selected Properties of 2-Ethyl-1-Hexanol ....................................................................................................................29

Table 10 - Summary of Aluminum Sample Analysis - Total, Soluble and Insoluble Al ...............................................31

Table 11 - Percent of Insoluble $\mathrm{Al}$ in the Feed that Precipitated during the Washing Cycle.

\section{LIST OF ACRONYMS}

KTPB

NaTPB

STTP

IIT B52

IIT PM

MST

ICP-ES

B2SS
Potassium Tetraphenylborate

Sodium Tetraphenylborate

Small Tank Tetraphenylborate Process

An antifoam agent prepared by Illinois Institute of Technology under contract to WSRC.

A particle modifier antifoam agent prepared by Illinois Institute of Technology under contract to WSRC.

Monosodium titanate

Inductively Coupled Plasma-Emission Spectroscopy

Bis(2-ethylhexyl)sodium sulfosuccinate - active ingredient in IIT B52 
WSRC-TR-2001-00102, REVISION 0

\subsection{EXECUTIVE SUMMARY}

IIT B52 antifoam was tested on a laboratory scale with simulated KTPB slurry using the proposed STTP process and simulated SRS salt waste solutions. The primary objective of these experiments was to determine the fate (partitioning) of the antifoam agent across the precipitation, concentration and washing cycles. In all cases, none of the active ingredient (bis(2-ethylhexyl)sodium sulfosuccinate, B2SS) in IIT B52 was found in the dilute, concentrated or washed precipitate slurry or in the filtrate from the concentration or washing cycle. A brief literature search revealed that bis(2-ethylhexyl)sodium sulfosuccinate undergoes hydrolysis in strong basic conditions (saponification) to form sodium sulfosuccinate and 2-ethyl-1-hexanol. Both bis(2-ethylhexyl) sodium sulfosuccinate and 2ethyl-1-hexanol have been used as antifoam agents in other industrial applications. Analytical results confirmed the presence of 2-ethyl-1-hexanol in the washed precipitate and in the filtrate collected during washing. Therefore, given the literature and analytical results, B2SS will hydrolyze in the STTP process to form 2-ethylhexanol and sodium sulfosuccinate. The analytical data indicates that the hydrolysis products are not concentrated during the concentration cycle. The hydrolysis reaction products are partially soluble in water and are expected to be present in the precipitate slurry and the filtrate.

A secondary objective of this experiment was to determine if insoluble aluminum formed during the STTP process. Insoluble aluminum, Gibbsite $(\mathrm{Al}(\mathrm{OH} 3))$ formed during the washing cycle using simulated KTPB slurries. Insoluble aluminum was not formed in the dilute or unwashed concentrated precipitate slurries or in the filtrate that was produced in the concentration and washing cycle. Less than $1 \%$ of the total aluminum fed to the process precipitated in the washing cycle. The insoluble aluminum composes less than $1 \%$ of the total mass of insoluble solids produced. Since the STTP process is designed to handle solids, the small quantity of aluminum that precipitated during the experiment should not have a significant effect on the overall process.

The IIT B52 antifoam affects the settling characteristics of the precipitate slurries. The insoluble solids in slurries produced without antifoam floated at the surface, whereas the washed and unwashed concentrated slurries produced with antifoam settled to the bottom of the test vessels and storage containers. Based upon this testing, as little as $100 \mathrm{ppmV}$ of IIT B52 significantly changes the settling characteristics of the concentrated precipitate slurry. This change in settling characteristics is explained by the fact that bis(2-ethylhexyl)sodium sulfosuccinate is a powerful and well characterized wetting agent.

Even under extreme agitation, foaming did not occur in precipitate slurries produced with or without antifoam during the precipitation cycle. Foaming did not occur in the concentration and washing cycles conducted with antifoam. If gas entrainment in the slurry is carefully avoided little or no foam will be generated during normal operations during concentration and washing of the precipitate. Ultimately, the STTP process should be designed to minimize the introduction of gas into the slurry during concentration and washing. However, gas can become entrained in the process via several mechanisms: 1) during startup and initial filling of the system, 2) by uncovering the agitator blades, 3) through use of pneumatic level/density

Page 1 of 34 
instrumentation, or 4) by entrainment of gas at the surface of the liquid during agitation. Therefore, antifoam will be required during concentration and washing. 
WSRC-TR-2001-00102, REVISION 0

\subsection{INTRODUCTION}

One of the alternatives to processing the highly radioactive salt solutions in the SRS Waste Tanks is to precipitate the highly radioactive cesium with sodium tetraphenylborate, then concentrate, and wash the precipitate slurry. Hydrolysis will be done in a new Salt Waste Disposition Facility (SWPF) prior to subsequent processing in the Defense Waste Processing Facility (DWPF). This alternative salt disposition process is called the Small Tank Tetraphenylborate Precipitation process (STTP). In the STTP process, soluble ions of cesium, potassium and ammonium are precipitated as insoluble TPB (tetraphenylborate) salts. Strontium, uranium, and plutonium are sorbed on solid monosodium titanate (MST). The resulting slurry, which now contains most of the radionuclides as insoluble solids, is filtered to concentrate the solids. After washing the solids to reduce the concentration of soluble sodium salts in the slurry, the precipitate is processed in the Salt Disposition Facility and incorporated into glass in the DWPF. The decontaminated salt solution or filtrate is transferred to Z Area for processing and disposal as Saltstone. ${ }^{1}$

Figure 1 is a schematic of the STTP process. The initial salt solution, $6.44 \mathrm{M}$ in Na (from tank 48 or $9.4 \mathrm{M}$ Na representing a composite of tanks as reported by Peterson in reference 3), is fed continuously into Precipitation Tank \#1 along with the volume of process water necessary to carry out the precipitation at the optimum concentration of $4.7 \mathrm{M} \mathrm{Na}$. Recycle wash water, MST and NaTPB solution (60\% excess TPB) is continuously fed into Precipitation Tank \#1. The precipitate slurry continuously overflows to a second identical Precipitation Tank \#2, which serves to increase the residence time for the precipitation process to 16-24 hours. The precipitation process is rapid. The rate-determining step is the adsorption of the plutonium, uranium and strontium on the MST solids. The slurry exiting Precipitation Tank \# 2 is $0.5-1.0$ wt. \% insoluble solids and is concentrated through a crossflow filter in the Concentrate tank to approximately $10 \mathrm{wt} \%$ insoluble solids. The concentrated slurry is then washed with dilute caustic $(0.01 \mathrm{M})$ using a crossflow filter to (1) reduce the nitrite to $\leq 0.01 \mathrm{M}$ for Precipitate Hydrolysis processing, (2) reduce the $\mathrm{Na}$ concentration to a level acceptable for glass production and (3) recover a portion of the excess NaTPB for recycle to Precipitate Tank \#1.

\footnotetext{
${ }^{1}$ R. A. Dimenna, et. al., Bases, "Assumptions, and Results of the Flowsheet Calculations for the Decision Phase Salt Disposition Alternatives", WSRC-RP-99-00006 Revision 0 9/30/99.
} 


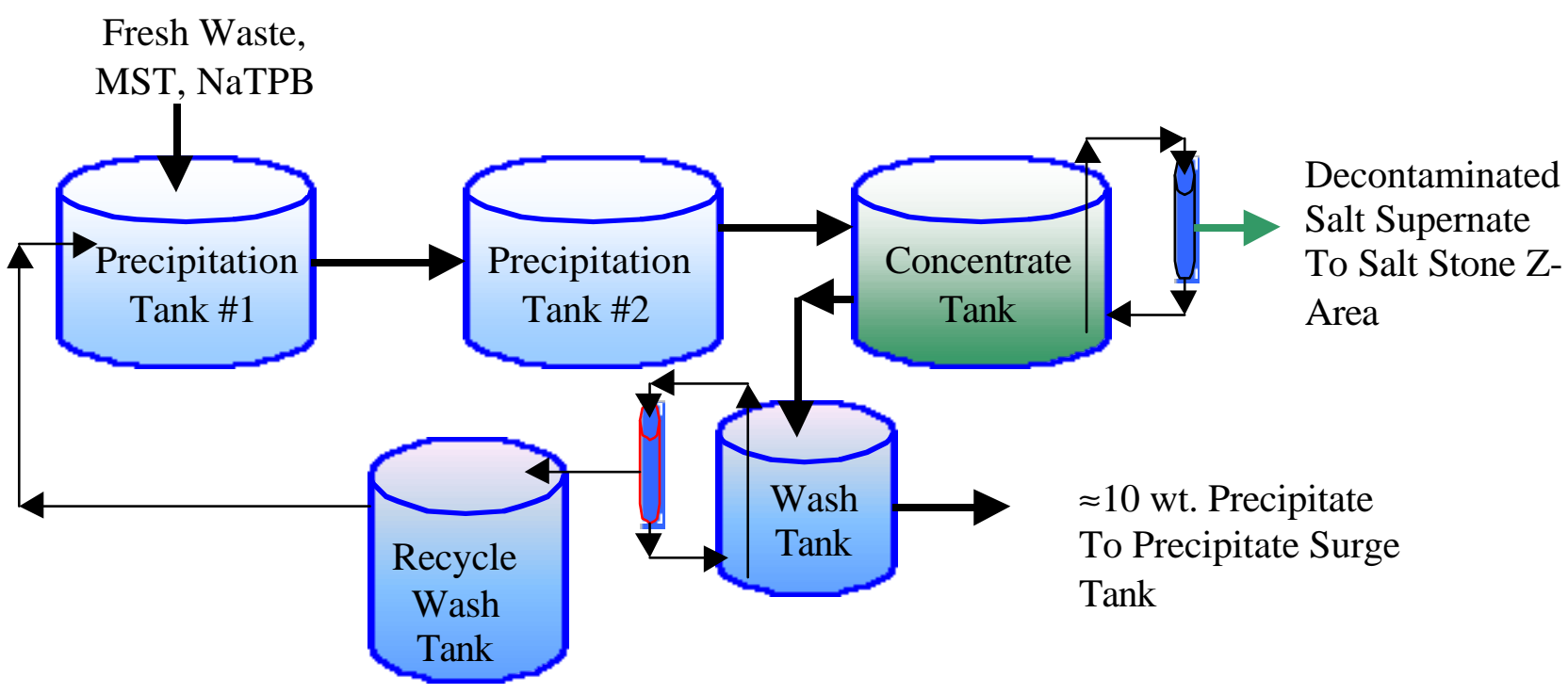

Figure 1 - Simplified Process Flow Diagram for the STTP Process

Excessive foaming was observed in tests of the precipitation process using actual SRS radioactive waste. ${ }^{2}$ Foaming was also observed in testing at ORNL using slurry spiked with radioactive cesium. ${ }^{3}$ Foaming during the precipitation, concentration and washing steps using simulants was also observed at SRTC. As a result of these experiences with foam generation, an investigation into finding suitable antifoam/defoam agents that can eliminate or mitigate the consequences of foam generation during normal operations of the proposed STTP process was completed by SRTC. ${ }^{4}$ These studies in conjunction with similar studies completed by ORNL recommended IIT B52 antifoamer for further testing. Furthermore, the SRTC and ORNL studies, concluded that IIT B52 antifoam appears to hinder the effectiveness of washing excess NaTPB from the concentrated slurry ${ }^{5,6}$. Nitrite washing does not appear to be affected by the presence of antifoam agent. The rheological properties

\footnotetext{
${ }^{2}$ R. A. Peterson and J. O. Burgess, "The Demonstration of Continuous Stirred Tank Reactor Operations with High Level waste", WSRC-TR-99-00345, Revision 1, February 15, 2000.

${ }^{3}$ D. D. Lee and J. L. Collins, "Continuous-Flow Stirred-Tank Reactor 20-L Demonstration Test: Final Report, ORNL/TM-1999/234.

${ }^{4}$ M. A. Baich, D. P. Lambert and P. R. Monson, "Laboratory Scale Antifoam Studies for the STTPB Process (U), WSRC-TR-2000-00261 Rev. 0, Westinghouse Savannah River Company, 10/24/2000.

${ }^{5}$ D. D. Lee, “Test Plan for CSTR Test 5”, CERS/SR/TPB/013, Oakridge National Laboratory, Oakidge, TN, 1/18/2001.

${ }^{6}$ D. D. Lee, "Test Results for CSTR Test 3", CERS/SR/TPB/011, Oakridge National Laboratory, Oakidge, TN, 9/27/2000.
} 
(consistency and yield stress) of the product slurries were reduced by the presence of antifoam agents.

As a result of previous testing conducted at SRTC and ORNL, SRTC was requested to determine the fate (partitioning) of IIT B52 antifoam agent across the Precipitation, Concentration, Washing and Hydrolysis Cycles ${ }^{7}$. The partitioning determination is needed to develop an antifoam addition strategy that ensures enough antifoam is present to minimize foaming without adding more antifoam than is needed. In addition, the Alternative Salt Disposition Scope of Work Matrix for STTP includes Objective 5.8, Evaluate downstream HLW system impacts of chosen antifoam agent.

This report describes the results of testing conducted using IIT B52 antifoam during the Precipitation, Concentration and Washing cycle using simulated SRS salt solutions. The fate of IIB52 during the Hydrolysis cycle will be discussed in a separate report. ${ }^{8}$ The objectives of these tests follows:

- Determine partitioning of IIT B52 across precipitation, concentration and washing,

- Determine if insoluble aluminum is formed during precipitation, concentration and washing,

- Prepare concentrated, washed potassium tetraphenylborate slurry for small-scale foaming experiments to be conducted by SRTC and IIT $^{12}$.

\subsection{MATERIALS AND METHODS}

\subsection{COMPOSITION OF SALT SOLUTION SIMULANTS.}

A stock solution of 4.7 M Na salt solution was prepared to simulate a composite of the high sodium HLW salt solution coming into Precipitation Tank \#1 in the precipitation process. The primary basis for the simulant recipe is the SRS Average Waste Simulant recipe ${ }^{9}$. Adjustments were made to the SRS average waste simulant to target the required $4.7 \mathrm{M} \mathrm{Na}$ concentration ${ }^{10}$. Purex sludge was added at $0.4 \mathrm{~g} / \mathrm{L}$ (g sludge solids $/ \mathrm{L}$ of precipitate) to simulate the entrained sludge that is present in SRS salt supernate. MST was added to target a concentration of $0.4 \mathrm{~g} / \mathrm{L}$ (g MST solids/L precipitate) in the precipitate solution. The

\footnotetext{
${ }^{7}$ D. P. Lambert, "Fate of IIT B52 Antifoam agent Across the Precipitation, Concentration, Washing and Hydrolysis Cycles", WSRC-RP-2000-00993 Rev. 0, Westinghouse Savannah River Company, 12/20/00.

${ }^{8}$ M. A. Baich, "IIT B52 Antifoam upon PBA Hydrolysis Kinetics", WSRC-TR-2001-00167, Westinghouse Savannah River Company, Aiken SC, April 2001.

${ }^{9}$ L. N. Oji and M. J. Barnes, "Batch studies of Sodium Tetraphenylborate Decomposition on Reduced Palladium", WSRC-TR-2000-00459 Rev. 0, Westinghouse Savannah River Company, 10/28/00

${ }^{10}$ D. L. Lambert, "Decision Summary of IIT B52 New Work Scope Meeting”, Email to H. D. Harmon et al., Westinghouse Savannah River Company, 1/10/01.
} 
potassium concentration was adjusted to achieve a target of $0.6 \mathrm{wt} . \%$ insoluble solids loading in the resulting precipitate slurry (including MST, sludge and CsTPB). Table 1 gives the typical composition of this salt solution. Ten identical 48.5 liter batches of this salt solution were made.

Table 1 - Composition for 1 Liter of 4.7 M Na Salt Solution Simulant

\begin{tabular}{|l|c|c|c|}
\hline \multicolumn{1}{|c|}{ Compound } & Conc. (M) & $\mathbf{N a}^{+} \mathbf{M}$ & Grams \\
\hline $\mathrm{NaOH}$ & 2.98 & 2.98 & 119.12 \\
\hline $\mathrm{NaNO}_{3}$ & 0.52 & 0.52 & 43.83 \\
\hline $\mathrm{NaNO}_{2}$ & 0.49 & 0.49 & 33.84 \\
\hline $\mathrm{Al}_{2}\left(\mathrm{NO}_{3}\right)_{3} \cdot 9 \mathrm{H}_{2} \mathrm{O}$ & 0.29 & & 109.76 \\
\hline $\mathrm{Na}_{2} \mathrm{CO}_{3} \cdot \mathrm{H}_{2} \mathrm{O}$ & 0.15 & 0.302 & 18.72 \\
\hline $\mathrm{Na}_{2} \mathrm{SO}_{4}$ & 0.14 & 0.283 & 20.12 \\
\hline $\mathrm{NaCl}$ & 0.02 & 0.02 & 1.37 \\
\hline $\mathrm{NaF}$ & 0.03 & 0.03 & 1.27 \\
\hline $\mathrm{Na}_{3} \mathrm{PO}_{4} \cdot 12 \mathrm{H}_{2} \mathrm{O}$ & 0.007 & 0.02 & 2.61 \\
\hline $\mathrm{Na}_{2} \mathrm{C}_{2} \mathrm{O}_{4}$ & 0.0075 & 0.015 & 1.006 \\
\hline $\mathrm{Na}_{2} \mathrm{SiO}_{3}$ & 0.0038 & 0.008 & 0.460 \\
\hline $\mathrm{Na}_{2} \mathrm{MoO}_{4} \cdot 2 \mathrm{H}_{2} \mathrm{O}$ & 0.0002 & 0.0004 & 0.054 \\
\hline $\mathrm{KNO}_{3}$ & 0.0091 & & 0.917 \\
\hline $\mathrm{CsNO}$ & 0.000013 & & 0.003 \\
\hline & Grams/liter & & 3.76 \\
\hline $\begin{array}{l}\mathrm{MST} \mathrm{Slurry} \mathrm{@} \mathrm{10.5} \\
\text { t. \% insoluble } \\
\text { solids }\end{array}$ & 0.4 & 0.0020 & \\
\hline $\begin{array}{l}\text { Purex Sludge Slurry } \\
\text { @ 21 wt. \% insoluble } \\
\text { solids }\end{array}$ & 0.4 & & 1.9 \\
\hline DI H & & & \\
\hline Total & & & 794.21 \\
\hline
\end{tabular}

Two experiments were planned: 1) $220 \mathrm{~L}$ with IIT B52 antifoam and 2) $272 \mathrm{~L}$ without antifoam. The NaTPB solution was $0.55 \mathrm{M}$ in NaTPB in $0.1 \mathrm{M} \mathrm{NaOH}$. Ten 1.6 liter batches of NaTPB solution were made. Previous work ${ }^{4}$ by SRTC and ORNL indicates that less NaTPB is recovered during the washing cycle when IIT B52 antifoam is added to control foaming. Therefore, the batch size of the antifoam run was reduced to account for the holdup of NaTPB in the precipitate slurry.

\subsection{COMPOSITION OF IIT B52 ANTIFOAM}

Table 2 summaries the two different batches of IIT B52 antifoam that were used for this experiment. 
WSRC-TR-2001-00102, REVISION 0

Table 2 - IIT B52 Antifoams used during Precipitation, Concentration and Washing Cycles - Note: only Batch 2 ANAEPG used during Washing Cycle

\begin{tabular}{|lccc|}
\hline Batch/Lot \# & Solvent & Effectiveness & Shipment Date from IIT \\
\hline Batch 3/CKWAN & Ethanol & $70 \%$ & $1-22-2001$ \\
\hline Batch 2/ANAEPG & Propylene glycol & $75 \%$ & $9-14-2001$
\end{tabular}

Originally, only Lot \# CKWAN (ethanol solvent) antifoam was planned for use in these experiments. Small-scale dilution studies showed that Lot \# CKWAN was relatively insoluble with water. Dilution studies using ethylene glycol ${ }^{11}$ and ethanol were conducted to determine the most effective diluent. The results of these studies are detailed in reference ${ }^{12}$. Based upon these studies, IIT B52 Lot \# CKWAN antifoam was prepared as 1:7.4 dilute solutions in ethanol (assuming a density of 1.0 for the antifoam). ${ }^{13}$

During the experiment, the mixture began to separate in the titrator pump into two separate liquid phases. Therefore, Batch 2 Lot\# ANAEPG was substituted for Batch 3 Lot\# CKWAN. This batch of antifoam agent was prepared as 1:100 dilute solution in DI water.

All diluted antifoam solutions were prepared on a volumetric basis.

\subsection{EXPERIMENTAL EQUIPMENT}

\subsubsection{Precipitation Process}

Two identical $30 \mathrm{~L}$ glass CSTR's were fabricated to simulate the precipitation process. One vessel was used to prepare precipitate slurry with antifoam and the other vessel was used to prepare precipitate without antifoam. A schematic of the precipitation vessels is show in Figure 2. These vessels had a sidearm at about the $21.5 \mathrm{~L}$ level to allow slurry from the CSTR to overflow into a collection tank. The vessel height, internal diameter, draft tube diameter, and draft tube length were geometrically scaled to a CSTR used in the Oakridge demonstration. The scaling calculations were preformed by M. Poirier ${ }^{14}$, SRTC WPT and the results are shown in Table 3.

\footnotetext{
${ }^{11}$ Ethylene glycol was used because it was readily available and was considered an alternative diluent by IIT.

12 I. Hickson, "Laboratory Scale Foam Column Studies", WSRC-TR-2001-00128 Rev. 0, Westinghouse Savannah River Company, 3/2001.

${ }^{13}$ Lot \# CKWAN was completely soluble in ethanol using a 1:5 dilution ratio. However, a 1:7.4 dilution ratio was used to bring the antifoam flowrate to the CSTR within the calibration range of the titrator pump used for this experiment.

${ }^{14}$ Personal Communication with Dr. Mike Poirier of WRSC, February 1, 2001.
} 
WSRC-TR-2001-00102, REVISION 0

Table 3 - CSTR Dimensions and Scaling Basis

\begin{tabular}{|l|c|c|c|}
\hline Vessel Parameter & SRTC CSTR, in. & Oakridge CSTR, in. & Scale Factor \\
\hline Height at Overflow & 13.1 & 11.6 & 1.13 \\
\hline Vessel Internal Diameter & 11.3 & 10.0 & 1.13 \\
\hline Draft Tube Diameter & 5.1 & 4.5 & 1.13 \\
\hline Draft Tube Length & 6.2 & 5.5 & 1.13 \\
\hline
\end{tabular}

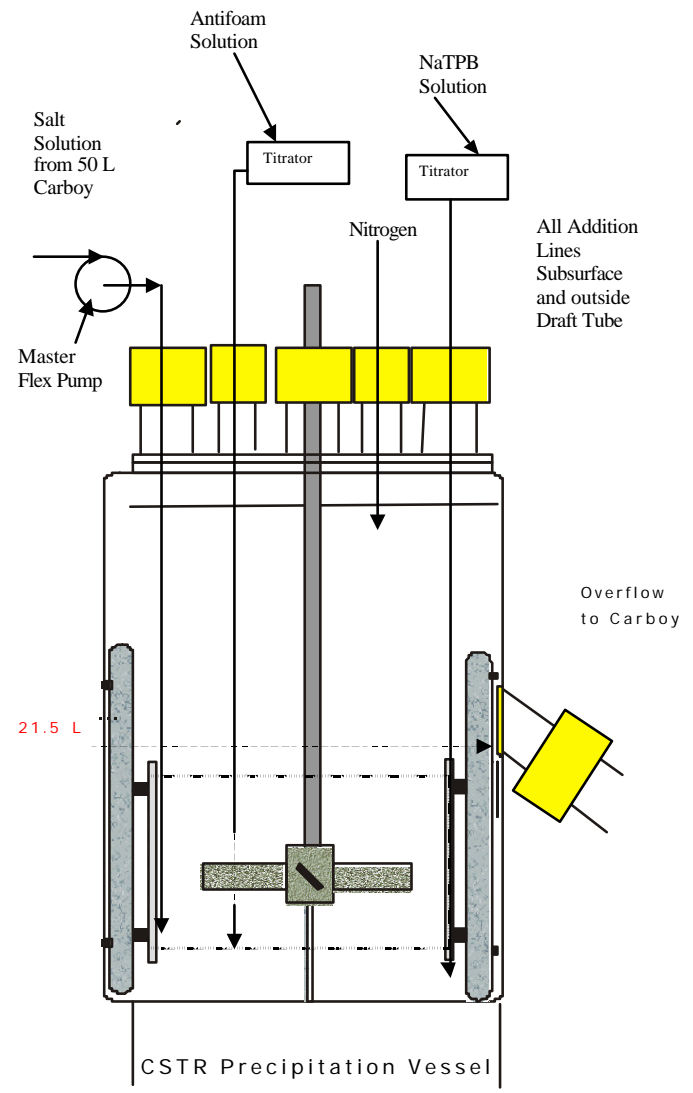

Figure 2 - Schematic of CSTR Precipitation System

Good mixing was achieved by using a four blade 3.4 inch diameter axial propeller at speeds up to 1000 RPM with four baffles $\left(0.94\right.$ " at $90^{\circ}$ to each other) in the tank. The solutions were pumped into the reaction vessels using calibrated peristaltic pumps and flexible tubing. The nitrogen purge is designed to exclude oxygen from the vapor space, preventing a flammable mixture from accumulating in the vessels or offgas system. The nitrogen purge gas was set to $100 \mathrm{sccm}$. The nitrogen purge gas was introduced into the top of each vessel, well above the liquid or foam level, and was controlled by a calibrated gas flow meter. The antifoam solution was metered into the CSTR using an automatic titrator at a concentration of $100 \mathrm{ppmV}$. 
The run parameters for the antifoam and non-antifoam precipitations are summarized in Table 4.

Table 4 - Precipitation Experimental Parameters

\begin{tabular}{||l|r|r||}
\hline \hline & $\begin{array}{c}\text { ANTIFOAM } \\
\text { RUN WITH IIT } \\
\text { B52 } \\
\text { ANTIFOAM }\end{array}$ & $\begin{array}{c}\text { NON-ANTIFOAM } \\
\text { BASELINE }\end{array}$ \\
\hline \begin{tabular}{|l|r||}
272 \\
Total Precipitate Volume @ 0.6 wt. \% insoluble solids
\end{tabular} & $220^{15}$ & 263.8 \\
\hline Total Salt Solution, L & 213.4 & 8.48 \\
\hline Total 0.55 M NaTPB, L & 6.9 & 0.6 \\
\hline Initial wt \% Insoluble Solids & 0.6 & $60 \%$ \\
\hline Excess NaTPB & 12 & 12 \\
\hline Estimated Washed Precipitate @ 10 wt. \%, L & 21.5 & 21.5 \\
\hline CSTR Size, L & 10 & 10 \\
\hline Residence Time, hrs & 34.8 & 34.8 \\
\hline Feed Rate, Salt Solution, ml/min & 1.12 & 1.12 \\
\hline Feed Rate, NaTPB Solution, ml/min & 100.0 & 0.0 \\
\hline Antifoam Concentration, ppmV & & \\
\hline
\end{tabular}

\subsubsection{Concentration and Washing Processes}

Figure 3 presents a drawing of the overall experimental setup for the concentration and washing steps. Mixing was achieved by using a four blade 3.4 inch diameter axial propeller at speeds up to 1000 RPM. The vessel did not have baffles.

During the concentration cycle, precipitate feed $(0.6 \mathrm{wt}$ \%) was added at rates up to 36 $\mathrm{ml} / \mathrm{min}$ to match the production rate of the precipitation process. The antifoam solution was metered into the CSTR, to maintain an antifoam level of $100 \mathrm{ppmV}$, with an automatic titrator. The antifoam concentration $(100 \mathrm{ppmV})$ assumes that the antifoam will be concentrated during the concentration cycle.

Precipitate feed was added using a peristaltic pump and flexible tubing via a subsurface diptube. The wash water $(0.01 \mathrm{M} \mathrm{NaOH})$ addition rate was controlled to maintain a constant level in the vessel. Filter feed pump suction and discharges were located near the bottom of

${ }^{15}$ Previous work ${ }^{4}$ by SRTC and others indicates that less NaTPB is recovered during the washing cycle when IIT B52 antifoam is added to control foaming. Therefore, the batch size of the antifoam run was reduced to account for the holdup of NaTPB in the precipitate slurry. 
the vessel. The level was lowered at the end of the wash cycle to achieve the desired wt. \% insoluble solids.

The crossflow filter was a Mott 0.5 micron stainless steel filter 6" long by "ID. The filter feed pump was low shear gas operated positive displacement pump.

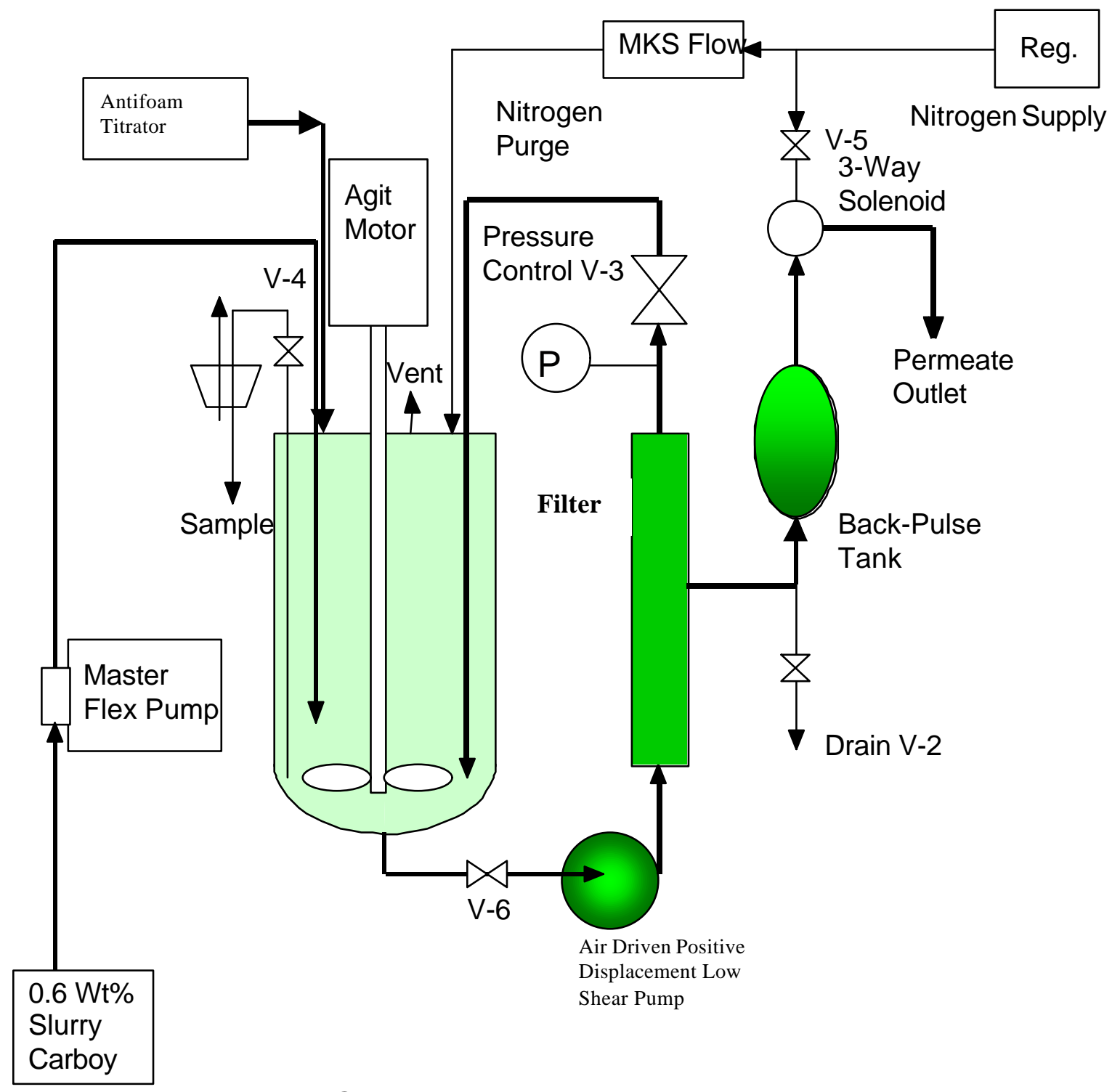

Cross Flow Filter Unit

Figure 3 - Schematic of Concentration and Washing Apparatus 


\subsection{DESCRIPTION OF EXPERIMENTS AND RESULTS}

\subsection{NO ANTIFOAM BASELINE}

The primary objectives of the No Antifoam Baseline test were:

1) Provide a baseline to compare the results obtained from the antifoam precipitation, concentration and washing tests,

2) Produce unwashed and washed precipitate slurry feed for foam column testing by SRTC and IIT.

\subsubsection{Precipitation Cycle}

The salt solution (Table 1) and NaTPB solutions were fed to the CSTR at a rate of 34.8 $\mathrm{ml} / \mathrm{min}$ and $1.12 \mathrm{ml} / \mathrm{min}$, respectively. Mass balances were maintained and the feed rate of the salt solution was adjusted slightly each day to maintain an average salt solution feed rate close to the desired rate of $34.8 \mathrm{ml} / \mathrm{min}$. Typically, the salt solution feed rate varied 1-2 $\mathrm{ml} / \mathrm{min}(<6 \%$ difference) from the desired rate. A calibration check was conducted for the NaTPB titrator pumps prior to conducting the experiment. The titrator pumps were periodically checked during the experiment and found to be within calibration. The vessel was prepurged with nitrogen at a rate of $500 \mathrm{sccm}$. The CSTR was purged with nitrogen at a rate of $100 \mathrm{sccm}$ during the precipitation cycle. The agitator was maintained at $750 \mathrm{rpm}$ during the entire duration of the experiment except for a brief portion of the test where the agitator speed was increased to $1000 \mathrm{rpm}$ to determine if the $0.6 \mathrm{wt}$. \% slurry would foam. The $1000 \mathrm{rpm}$ foaming test with $0.6 \mathrm{wt}$. \% precipitate slurry will be discussed in the section 4.2 of this report.

At the end of a twelve-hour shift the feed pumps, agitator, and nitrogen purge were stopped until the next day. The system was inventoried on the first day of the experiment and precipitate was produced on the subsequent shifts.

Little (less than $5 \%$ ) foam was observed in the CSTR during the No Antifoam Baseline test. This indicates the precipitation can be carried out without foaming if gas is not injected into the slurry. During the initial filling of the CSTR, some foam developed between each of the baffles in the tank as shown in Figure 4. This foam build up is likely due to the poor mixing in the vessel that occurs when the level is below the draft tube. The level of foam stabilized to values well less than 5\% after 2 days of steady operation. The level of foam (nearly zero \% foaminess) after fourteen days of steady state operations is shown in Figure 5.

More details of the run can be found in the Run Plan document, SRT-ITB-2001-002 Rev. 1, February 21, 2001 by T. B. Calloway. 


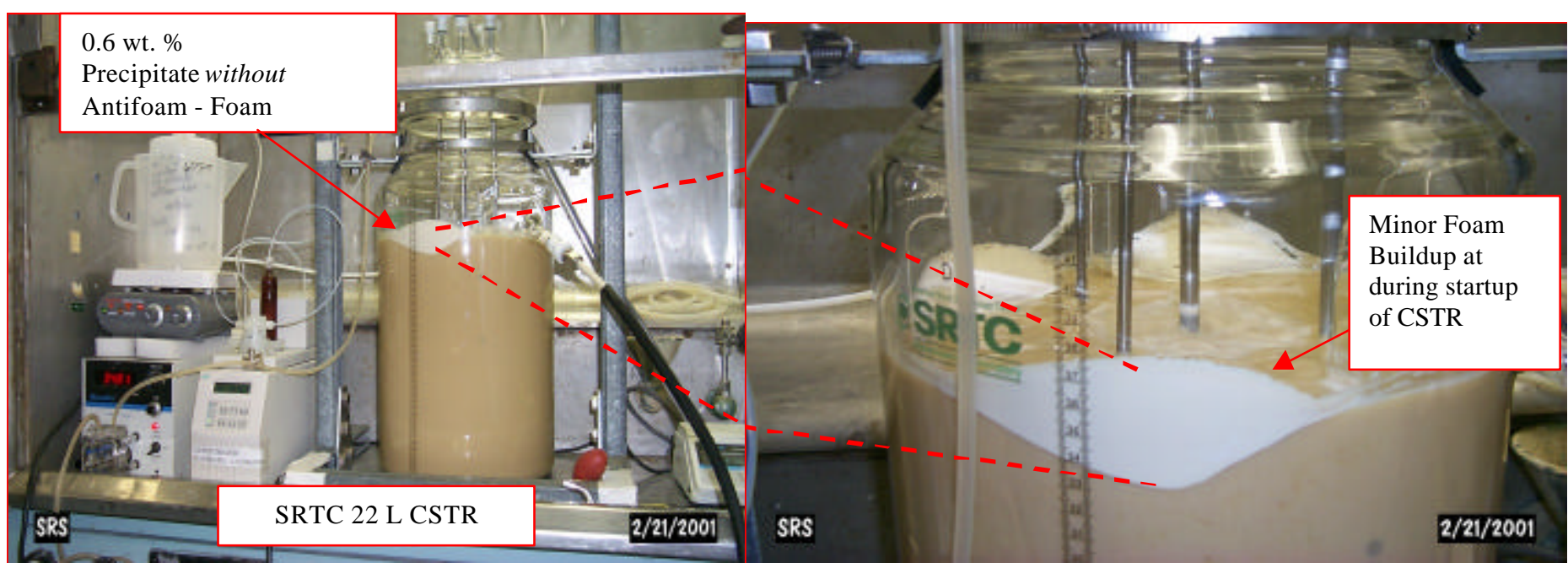

Figure 4 - Non Antifoam Test CSTR Precipitation Cycle Agitator at 750 rpm - Minor foam buildup during initial startup of CSTR

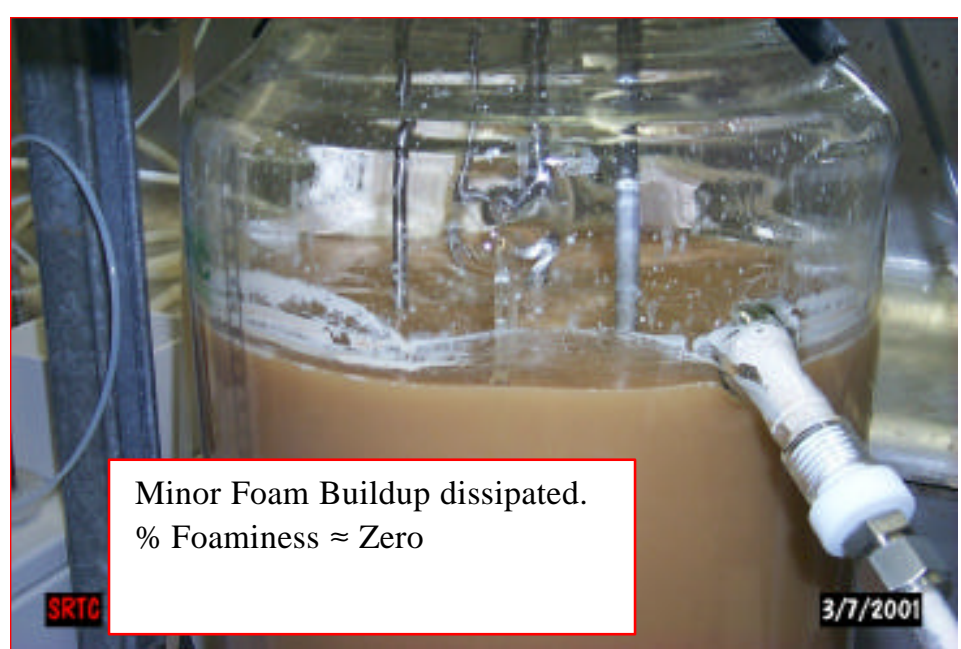

Figure 5 - Non Antifoam Test CSTR Precipitation Cycle - Agitator at 750 rpm after 14 days of Operation 


\subsubsection{Concentration and Washing Cycle}

One concentration cycle with no antifoam addition was completed. The $0.6 \mathrm{wt} . \%$ precipitate was fed to the crossflow filtration rig at a nominal flowrate of $15-30 \mathrm{ml} / \mathrm{min}$. The agitator was maintained at $550 \mathrm{rpm}$. This speed was selected because it kept the vessel well mixed but was not high enough to create a vortex that would draw gas into the slurry. The slurry was concentrated to approximately $10 \mathrm{wt}$ \% insoluble solids and samples were taken and submitted for analysis by gravimetry (Microwave and Halogen systems). Sample analysis shows the concentrated precipitate slurry to be $10.8 \mathrm{wt}$. \% insoluble solids. No foaming was observed during the concentration cycle.

Wash water requirements were calculated using a well-mixed model assuming constant wash water and permeate flow rates. Total slurry volume was used instead of the volume of salt solution contained in the $10 \mathrm{wt}$. \% slurry. The salt solution nitrite concentration was used as the initial nitrite concentration. The desired washed slurry nitrite target was $0.0089-0.011 \mathrm{M}$ $(410-510 \mathrm{mg} / \mathrm{L})$. This calculation is presented below:

$$
\text { Wash Water }(23351 \mathrm{ml})=[\text { Slurry Volume }(6000 \mathrm{ml})] \times \ln \left[\frac{\operatorname{Initial~Nitrite}(0.49 \mathrm{M})}{\operatorname{Final~Nitrite}(0.01 M)}\right]
$$

Equation [1]

Wash Water was added to maintain a constant level in the vessel. The agitator speed was set at $550 \mathrm{rpm}$ at the start of washing. This speed was selected because it kept the vessel well mixed but was not high enough to create a vortex that would draw gas into the slurry. Prior to restarting the system after the first shift of washing, a significant layer of foam $(\approx 30 \%)$ was found on the liquid surface. The resulting foam is shown in Figure 6 . This is likely due to the decrease in apparent viscosity of the concentrated precipitate that results when soluble sodium is removed during the washing cycle. The decrease in viscosity probably resulted in an increase in the agitator vortex depth that allowed a small quantity of gas to be drawn into the slurry. Agitator vortex depth is known to increase with a decrease in the viscosity of the fluid being mixed ${ }^{16}$. While a slight vortex was observed during the run, it was not clear whether it was large enough to draw gas into the slurry. The foam was very stable and would not break up with the agitator set at $550 \mathrm{rpm}$. Since the foam contained a large fraction of the total insoluble solids, the washing cycle might not achieve the desired target nitrite concentration $(0.01 \mathrm{M})$. Therefore, an attempt was made to incorporate the solids by using a higher agitator speed $(1000 \mathrm{rpm})$ for a brief period of time $(\approx 30 \mathrm{~min})$. While the attempt to incorporate the solids proved to be successful, the higher agitator speed increased the level of foam as shown in Figure 6.

\footnotetext{
${ }^{16}$ F. Rieger, P. Ditl, V. Novak, "Vortex Depth in Mixed Unbaffled Vessels", Chemical Engineering Science, Vol. 34, pp397 -401, 1979.
} 
Ultimately, the STTP process should be designed to minimize the introduction of gas into the slurry during concentration and washing. However, gas can become entrained in the process via several mechanisms: 1) during startup and initial filling of the system, 2) by uncovering the agitator blades, 3) through use of pneumatic level/density instrumentation, or 4) by entrainment of gas at the surface of the liquid. The operating experience indicates that even under very well controlled laboratory conditions, the formation of KTPB foam is not a recoverable event without the use of antifoam. 


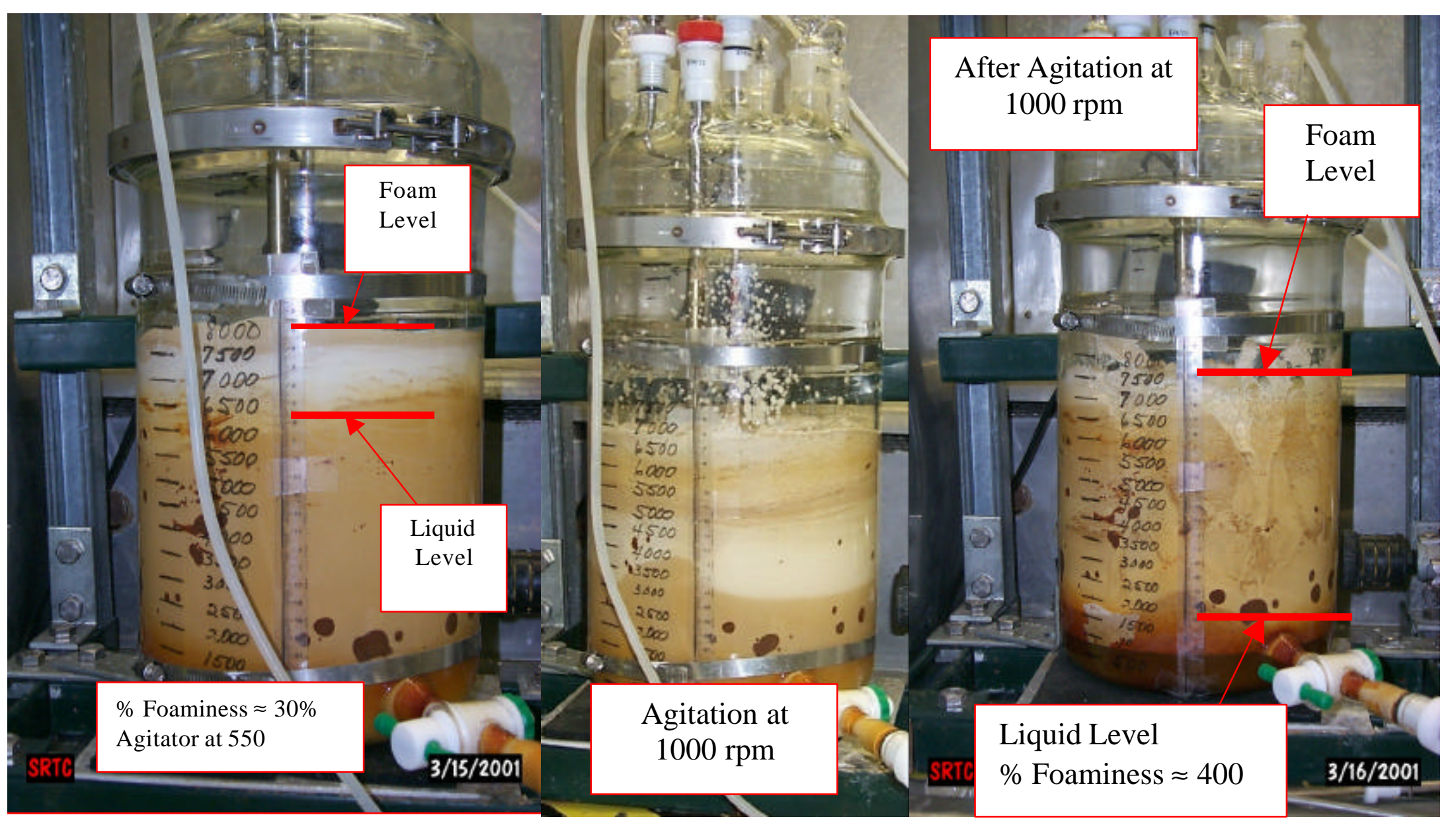

Figure 6 - Non Antifoam Baseline Test During Washing of 10 wt. \% Precipitate - Agitator Speed at 550 rpm and 1000 rpm 


\subsection{ANTIFOAM RUN WITH IIT B52}

The primary objectives of the Antifoam test were:

1) Determine partitioning of IIT B52 across precipitation, concentration and washing cycles,

2) Produce unwashed and washed precipitate slurry feed with IIT B52 for foam column testing by SRTC and IIT,

3) Determine if insoluble aluminum is formed during the precipitation, concentration or washing cycles.

\subsubsection{Precipitation Cycle}

The salt solution (Table 1) and NaTPB solutions were fed to the CSTR at a rate of 34.8 $\mathrm{ml} / \mathrm{min}$ and $1.12 \mathrm{ml}$, respectively. Mass balances were maintained and the feed rate of the salt solution was adjusted slightly each day to maintain an average salt solution feed rate close to the desired rate of $34.8 \mathrm{ml} / \mathrm{min}$. Typically, the salt solution feed rate varied $1-2 \mathrm{ml} / \mathrm{min}(<6$ $\%$ difference) from the desired rate. A calibration check was conducted for the NaTPB titrator pumps prior to conducting the experiment. The titrator pumps were periodically checked during the experiment and found to be within calibration. The vessel was prepurged with nitrogen at a rate of $500 \mathrm{sccm}$. The CSTR was purged with nitrogen at a rate of 100 $\mathrm{sccm}$. At the end of a twelve-hour shift the feed pumps, agitator, and nitrogen purge were stopped until the next day. The system was inventoried on the first day of the experiment and precipitate was produced on the subsequent days of the experiment.

The agitator was maintained at $750 \mathrm{rpm}$ during the entire duration of the experiment except for a brief portion of the test where the agitator speed was increased to $1000 \mathrm{rpm}$ to determine if the 0.6 wt. \% slurry would foam.

The precipitate slurry produced in the CSTR was sampled and analyzed for insoluble solids by gravimetry (Microwave and Halogen systems). Sample analyses (average of 6 values, standard deviation $=0.22 \%$ ) show the precipitate slurry to be $0.58 \mathrm{wt}$. \% insoluble solids.

Figure 7 shows the non-antifoam test with the agitator operating at 750 and $1000 \mathrm{rpm}$. The agitator was operated at $1000 \mathrm{rpm}$ for 1 hour. While a noticeable layer of foam developed at $1000 \mathrm{rpm}$, the foam was unstable and quickly dissipated after the agitator was shutdown. Figure 8 shows the precipitation cycle using the IIT B52 antifoam. There is a small measurable difference ( $2 \%$ foaminess vs. $4 \%$ ) between the precipitation test with antifoam and the precipitation test without antifoam. The antifoam was added to the CSTR at 100 ppmV. Little (less than $4 \%$ ) foam was observed in the non-antifoam and antifoam CSTR during the precipitation cycle even when gas was introduced into the slurry by extreme agitation. 
Two different batches of IIT B52 antifoam were used during the experiment. Initially, Batch 3 (Lot \# CKWAN) antifoam was diluted by volume with ethanol (7.4 parts ethanol : 1 part IIT B52 Antifoam). The Batch 3 antifoam was added to the CSTR to maintain the antifoam concentration at approximately $100 \mathrm{ppmV}(0.03 \mathrm{ml}$ diluted antifoam $/ \mathrm{min})$. During the experiment, the Batch 3 mixture began to separate in the titrator pump into two separate liquid phases. Therefore, antifoam from Batch 2 Lot\# ANAEPG was used. This batch of antifoam agent was prepared as 1:100 dilute solution in DI water. The Batch 2 antifoam was added to the CSTR to maintain the antifoam concentration at approximately $100 \mathrm{ppmV}(0.37 \mathrm{ml}$ diluted antifoam $/ \mathrm{min}$ ). Batch 2 and 3 contain only 75 and $70 \%$ of the active antifoam agent, respectively. Therefore, the calculated active agent concentration in the CSTR was $70 \mathrm{ppmV}$ for Batch 3 and $75 \mathrm{ppmV}$ for Batch 2. Given the variability of the salt solution feed pumps (1-2 $\mathrm{ml} / \mathrm{min})$, the calculated active agent concentration in the CSTR varied between $66-74$ $\mathrm{ppmV}$ for the portion of the run conducted with Batch 3 antifoam and $71-79 \mathrm{ppmV}$ for the portion of the run conducted with Batch 2 antifoam. The actual quantities of antifoam used during the experiment are discussed in section 4.2.3.

However, results from IIT B52 analysis (See section 4.2.3 for further discussion of IIT B52 analytical results) indicated that the active ingredient in IIT B52 was broken down under the strong caustic conditions.

The IIT B52 addition rate was increased (calculated concentration raised to 400 and 1000 $\mathrm{ppmV}$ ) for a short duration (60 minutes) to determine if the change had a noticeable effect of the formation of foam in the CSTR. The time duration for the test was selected because preliminary analytical results indicated that the IIT B52 degraded within 30 - 60 minutes after addition to the precipitate slurry. After the agitator was allowed to operate at $1000 \mathrm{rpm}$ for one hour, the antifoam addition rate was changed to equal approximately $400 \mathrm{ppmV}$ (1.48 $\mathrm{ml} / \mathrm{min}$ diluted antifoam). The system was allowed to agitate for 60 minutes and a picture of the liquid foam interface was taken. The antifoam addition rate was then changed to equal approximately $1000 \mathrm{ppmV}(3.7 \mathrm{ml} / \mathrm{min}$ diluted antifoam). The system was allowed to agitate for 60 minutes and a picture of the liquid foam interface was taken. The antifoam addition rate was then changed back to the original rate $(0.37 \mathrm{ml} / \mathrm{min}, 100 \mathrm{ppmV})$. The actual concentration of antifoam in the pot was much less then the quoted values since the CSTR has a ten-hour residence time. Figure 9 shows the CSTR with the agitator running at $1000 \mathrm{rpm}$ at various antifoam concentrations. There is a clear difference between the size of the bubbles at 100, 400 and $1000 \mathrm{ppmV}$. Figure 9 shows the smaller nitrogen bubbles coalescing into larger less stable foams at antifoam flow rates equivalent to concentrations of 400 and $1000 \mathrm{ppmV}$. The vessel has a ten-hour residence time so the actual concentration of antifoam in the vessel is much less than 400 and $1000 \mathrm{ppmV}$. Since the antifoam is less dense than the salt solution, the concentration at the liquid surface may in fact be close to 400 and $1000 \mathrm{ppmV}$ as shown in Figure 9. 
WSRC-TR-2001-00102, REVISION 0

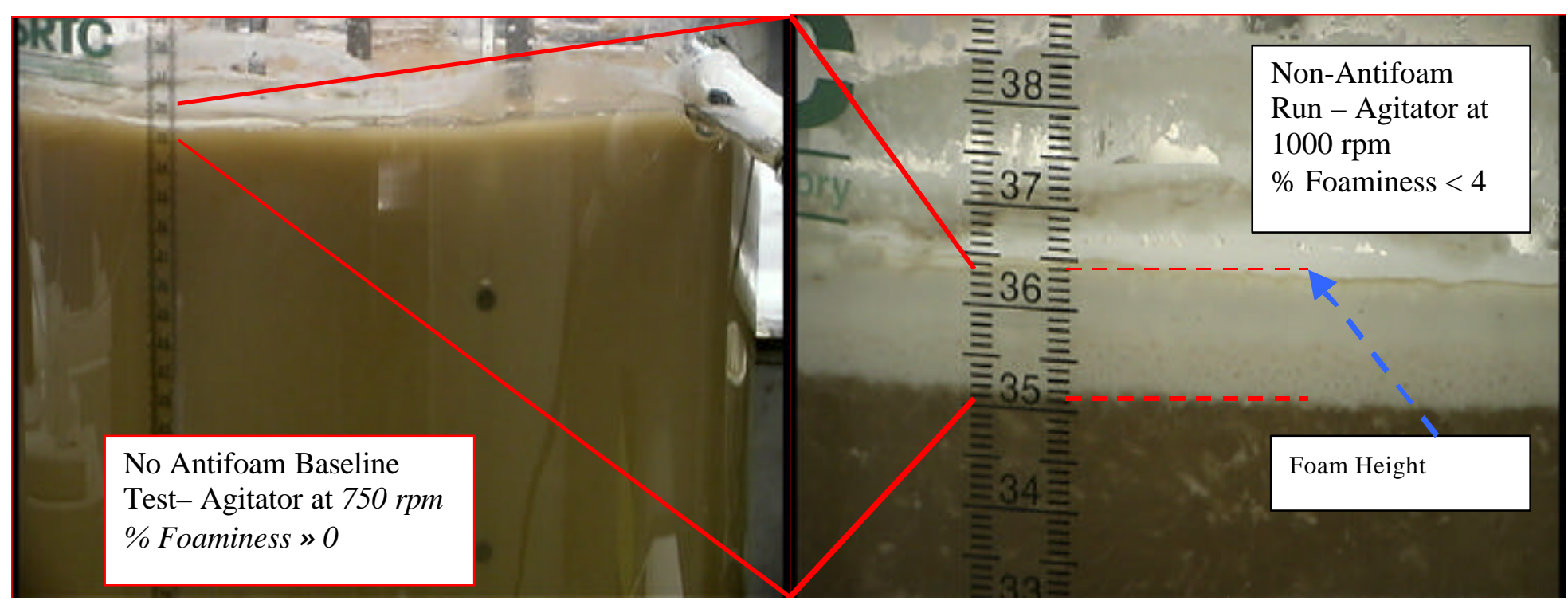

Figure 7 - Precipitation Cycle No Antifoam Test - Agitator at 750 and 1000 rpm

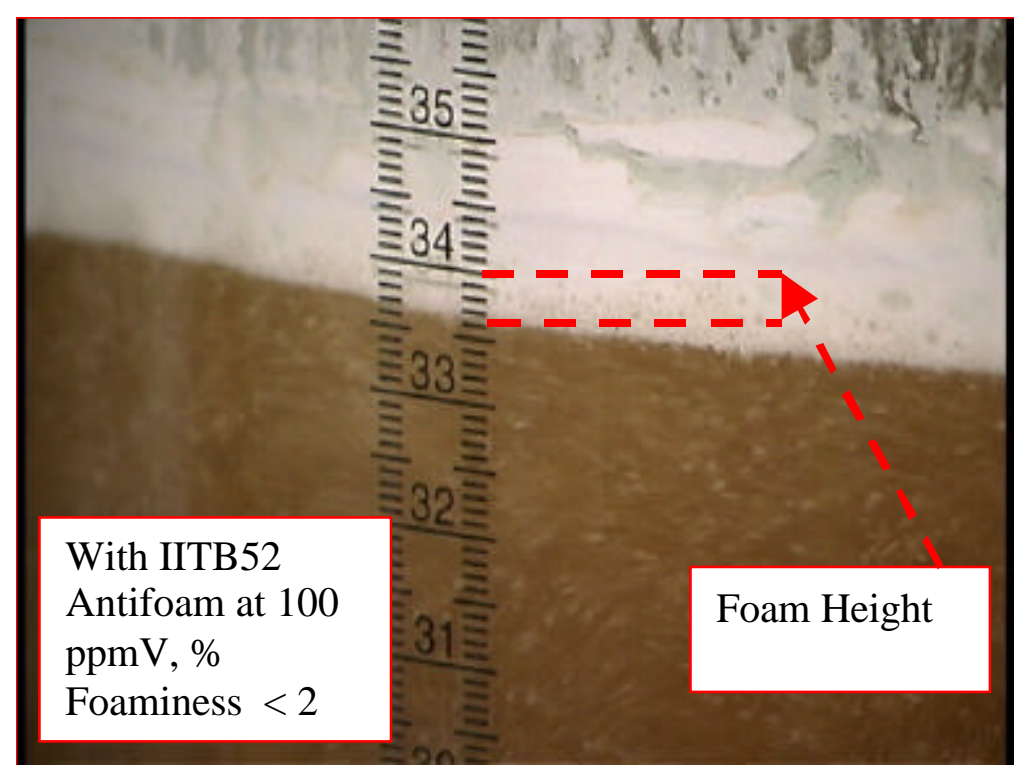

Figure 8 - Precipitation Cycle Antifoam Test with IIT B52 - Agitator at 1000 rpm 


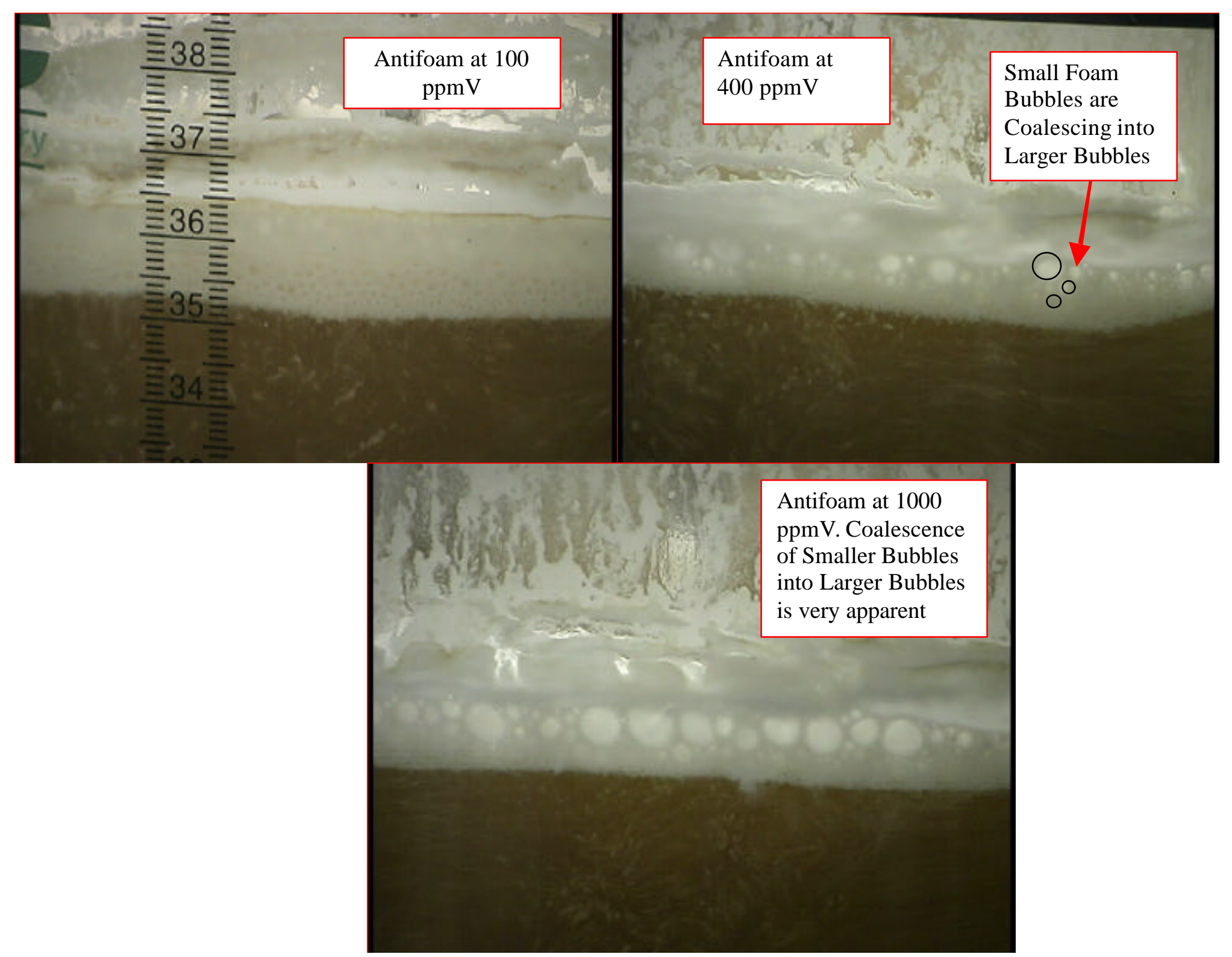

Figure 9 - Precipitation Cycle with IIT B52 Antifoam at Various Antifoam Concentration - As antifoam concentration increases, the Coalescing Action of the Antifoam Increases 
WSRC-TR-2001-00102, REVISION 0

\subsubsection{Concentration and Washing}

One concentration cycle with antifoam addition was completed. The $0.6 \mathrm{wt}$. \% precipitate was fed to the cross flow filtration rig at a nominal flowrate of $36 \mathrm{ml} / \mathrm{min}$. The flowrate was varied to maintain a constant level in the vessel. The antifoam addition rate was set to achieve a concentration of $100 \mathrm{ppmV}$. The cross flow filter was started up using Batch 3 antifoam. For reasons previously mentioned, Batch 2 Lot\# ANAEPG was substituted for Batch 3 antifoam. This batch of antifoam agent was prepared as 1:100 dilute solution in DI water. The Batch 2 antifoam was added to the CSTR to maintain the antifoam concentration at approximately $100 \mathrm{ppmV}(0.37 \mathrm{ml}$ diluted antifoam $/ \mathrm{min})$. The agitator was maintained at $550 \mathrm{rpm}$. This speed was selected because it kept the vessel well mixed but was not high enough to create a vortex that would draw gas into the slurry. No foaming was observed during the concentration cycle.

The glass pump inlet nozzle on the concentration/washing vessel failed at the end of the concentration cycle. The failure was likely due to stress caused by vibration from the low-shear gas operated diaphragm pump. The concentrated slurry leaked into the secondary containment and was recovered. A new vessel was installed and the experiment proceeded without further incident.

The slurry was concentrated to approximately $10 \mathrm{wt} . \%$ insoluble solids and samples were taken and submitted for analysis by gravimetry (Microwave and Halogen systems). Sample analysis showed the concentrated precipitate slurry to be $10.1 \mathrm{wt}$. \% insoluble solids. As the batch was concentrated, the antifoam concentration should also have increased. However, analytical results show that no IIT B52 antifoam was present in the concentrated precipitate or in the filtrate collected during concentration (See section 4.2.3). The active ingredient in the antifoam was probably broken down under the strong caustic conditions.

Wash water requirements were calculated using a well-mixed model assuming constant wash water and permeate flow rates. Total slurry volume was used instead of the volume of salt solution contained in the $10 \mathrm{wt}$. \% slurry. The salt solution nitrite concentration was used as the initial nitrite concentration. The desired washed slurry nitrite target was $0.0089-0.011 \mathrm{M}(410-510 \mathrm{mg} / \mathrm{L})$. This calculation is presented below:

Wash Water $(17513 \mathrm{ml})=[$ Slurry Volume $(4500 \mathrm{ml})] \times \ln \left[\frac{\operatorname{Initial} \text { Nitrite }(0.49 \mathrm{M})}{\text { Final Nitrite }(0.01 \mathrm{M})}\right]$

Equation [2]

Wash Water was added to maintain the vessel at a constant level. The agitator speed was set at $550 \mathrm{rpm}$ at the start of washing. This speed kept the vessel well mixed but was not high enough to create a vortex that would draw gas into the slurry. Batch 2 antifoam was used during washing.

Since the filtration flux was lower than the planned rate of $36 \mathrm{ml} / \mathrm{min}$, the $0.6 \mathrm{wt} . \%$ precipitate slurry flowrate had to be decreased to maintain a constant level in the cross flow filtration 
WSRC-TR-2001-00102, REVISION 0

concentration/washing vessel. The precipitate slurry flow rate during washing varied between 11 to 20 $\mathrm{ml} / \mathrm{min}$ with an average flowrate of approximately $16 \mathrm{ml} / \mathrm{min}$. The Batch 2 antifoam was added to the cross flow filtration concentration to maintain the antifoam concentration at approximately $100 \mathrm{ppmV}$ $(0.37 \mathrm{ml}$ diluted antifoam $/ \mathrm{min})$. The concentration of active ingredient in Batch 2 antifoam is $75 \%$. Therefore, given the variability of the filtration flux $\left(\approx 11-20 \mathrm{ml} / \mathrm{min}, 0.023-0.040 \mathrm{gal} / \mathrm{min} / \mathrm{ft}^{2}\right)$, the calculated antifoam concentration in the washing vessel varied between $130-210 \mathrm{ppmV}$. The average antifoam concentration during washing was calculated to be $150 \mathrm{ppmV}$. However, analytical results show that no IIT B52 antifoam was present in the washed precipitate or in the filtrate collected during washing.

The effectiveness of IIT B52 antifoam during washing is compared to the no antifoam run in Figure 10. No foaming occurred during the washing cycle using IIT B52 antifoam. However, no gas was introduced into the precipitate slurry with antifoam and the agitator speed was intentionally set to prevent a vortex while still maintaining a well-mixed tank. The liquid surface of the slurry with antifoam appeared to be well wetted compared to the slurry without antifoam. The slurry without antifoam appeared to be broken up with solids and foam. Brown stains appeared on the glass vessel in the No Antifoam Run during the concentration and washing cycle. However, as Figure 10 shows the brown stain did not appear on the vessel in the antifoam run. The formation of these stains is thought to be a mixture of MST and sludge. The antifoam appears to have fully wetted and acted as an agitation aid for the sludge and MST solids. The formation of these stains should be investigated by future research studies.

The slurry was concentrated to approximately $10 \mathrm{wt} . \%$ insoluble solids and samples were taken and submitted for analysis by gravimetry (Microwave and Halogen systems). Sample analysis show the concentrated precipitate slurry to be $11.2 \mathrm{wt}$. \% insoluble solids. The slurry with antifoam appeared to be less viscous than the washed precipitate slurry without antifoam. 


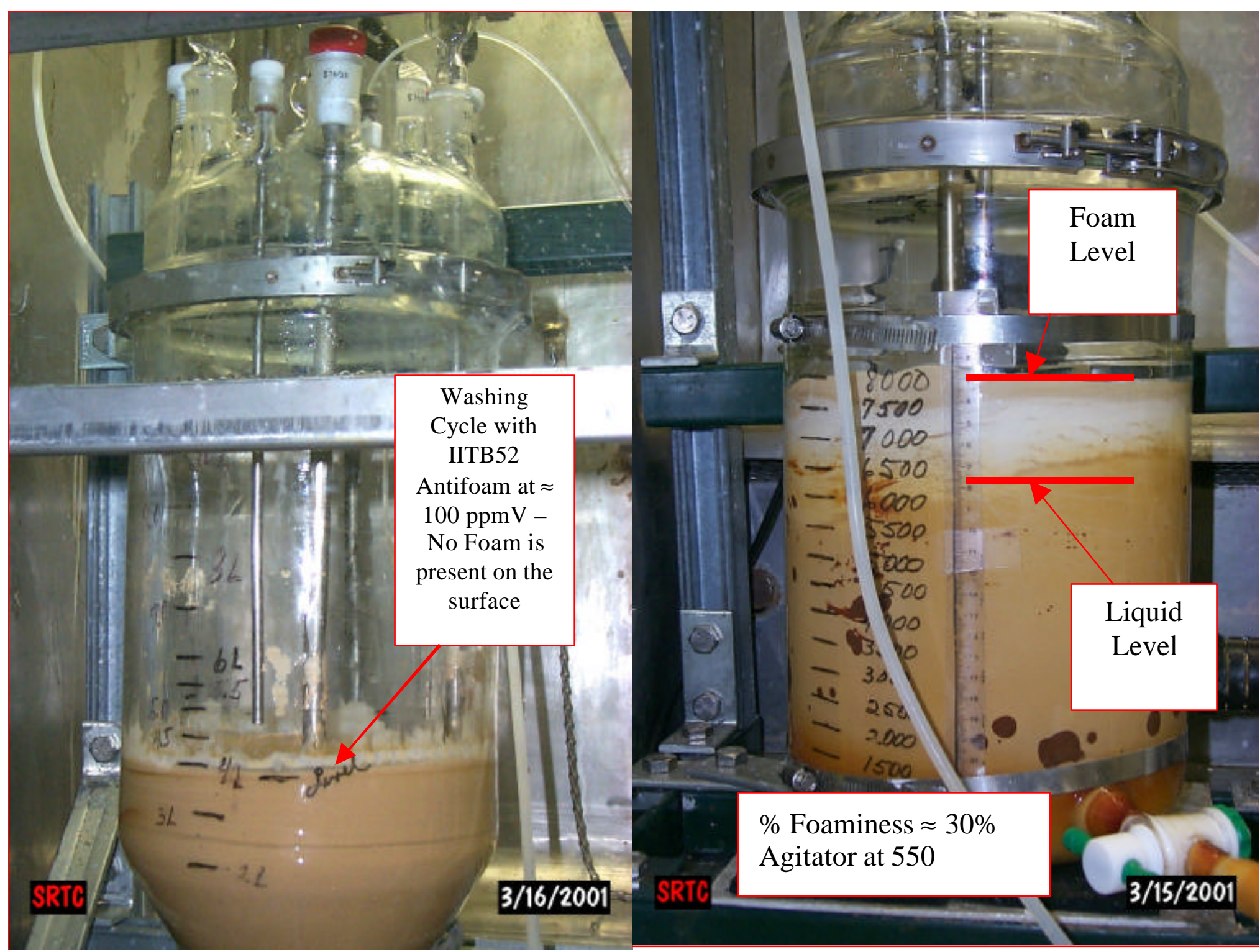

Figure 10 - Comparison of STTP Washing Cycle With and Without Antifoam 
After the experiment was completed, all the concentrated slurries (with and without antifoam, washed and unwashed samples) produced by the experiment were stored and allowed to settle. All the insoluble solids in the concentrated slurries containing IIT B52 antifoam settled to the bottom of the storage container. The insoluble solids in the slurries without antifoam floated at the top of the container and appeared to have a small foam layer. Unwashed samples (4 wt. \%) of KTPB slurry, with and without antifoam, were placed in graduated cylinders to show the impact of the IIT B52 antifoam. Figure 11 shows that the density of the insoluble solids in slurries prepared using IIT B52 are clearly greater than the density of the supernate $(\approx 1.2 \mathrm{~g} / \mathrm{ml})$ causing the solids to settle to the bottom of the cylinder. Organic (e.g. benzene) micelles that are formed during the decomposition of TPB are thought to be electrostatically attached to insoluble TPB particles causing the density of the TPB particle to be less than the density of the supernate. Clearly, IIT B52 antifoam acts as a powerful wetting agent and affects the physical properties of the precipitate slurry.

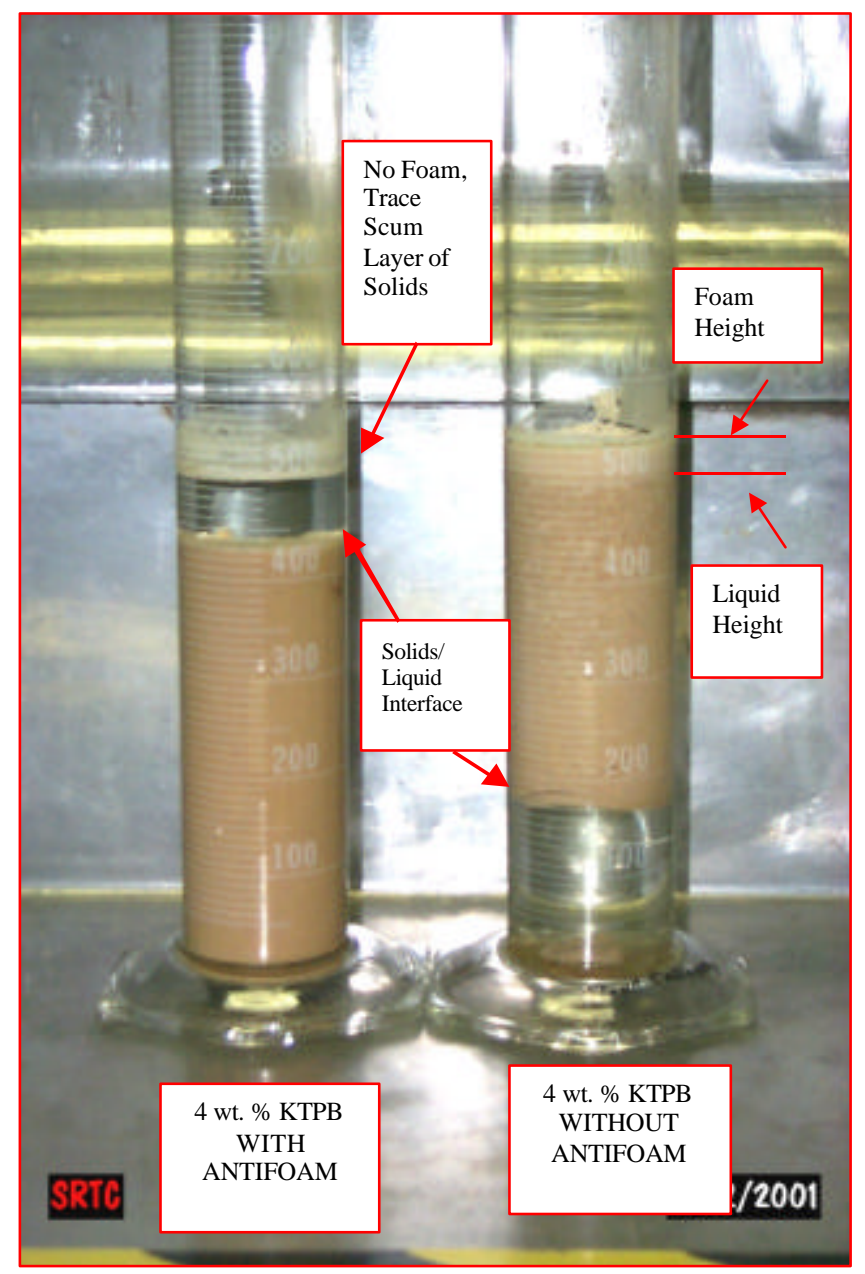

Figure 11 - Comparison of Typical Precipitate Slurries Prepared With and Without IIT B52 Antifoam

IIT B52 antifoam was added to the graduated cylinder (4 wt. \% KTPB without antifoam) shown in Figure 11. Figure 11 also shows a sample of 4 wt. \% KTPB slurry produced using 
the STTP process using IIT B52 antifoam. The slurry used for this test was produced in the No antifoam baseline run. The Batch 2 antifoam was added at a concentration of $100 \mathrm{ppmV}$ and agitated with a magnetic stirrer for 30 minutes. The foam on the surface broke down within minutes after the agitator was started. The slurry was allowed to settle for 48 hours and a picture was taken. The results are shown in picture No. 1 in Figure 12. The floating solids were evenly dispersed throughout the cylinder by the wetting action of the antifoam. For comparison, a settled sample of 4 wt. \% KTPB slurry produced using $100 \mathrm{ppmV}$ antifoam and the laboratory scale STTP process is also shown in Picture No. 1 in Figure 12 (same sample as Figure 11).

After settling and aging for 48 hours, antifoam was added to the slurry shown in Picture No. 1 (4wt. \% KTPB without antifoam) at a concentration of $150 \mathrm{ppmV}$ and agitated for 30 minutes. The slurry was allowed to settle for 48 hours. The results are shown in Picture No. 2 in Figure 12. A clear liquid-solid interface is shown in the picture. This test confirms that IIT B52 affects the settling characteristics of the precipitate slurry. Since all the washed concentrated slurries produced for this task had similar settling characteristics to those shown in Picture No. 2 in Figure 12, the true concentration of IIT B52 was probably closer to 150 ppmV during the washing cycle. This is consistent with the calculated value $(\approx 150 \mathrm{ppmV})$ derived earlier in this report.

Figure 11 and Figure 12 demonstrate that IITB52 is a strong wetting agent in the KTPB matrix. 


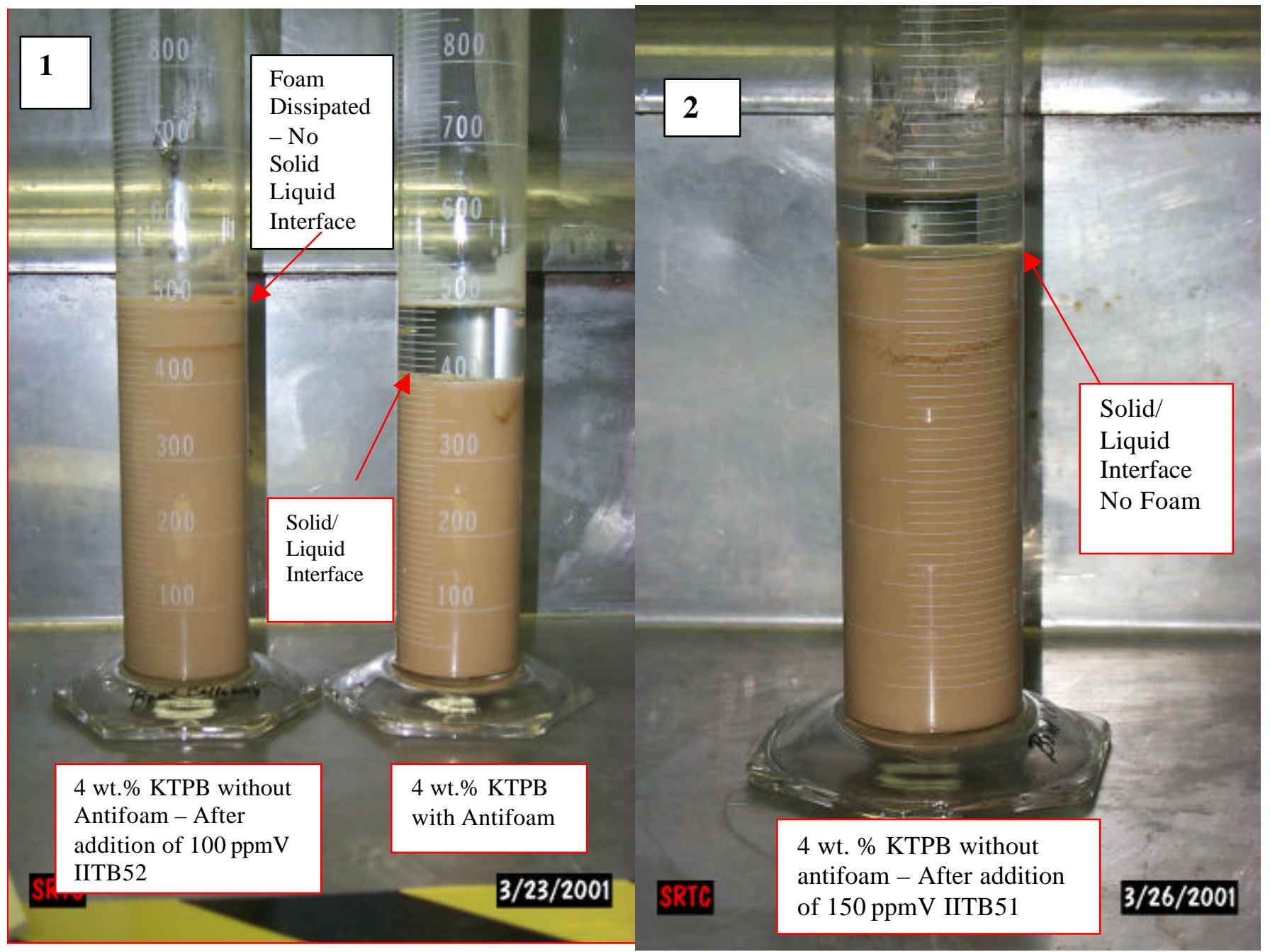

Figure 12 - Comparison of 4 wt. \% Precipitate Slurries after the addition of antifoam at 100 and $150 \mathrm{ppmV}$. 


\subsubsection{IIT B52 Sample Analysis}

The active chemical in IIT B52 is Bis(2-ethylhexyl)sodium sulfosuccinate (B2SS). The acronym B2SS will be used to describe the active ingredient in IITB52.

Samples of dilute precipitate $(0.6 \mathrm{wt} . \%)$, concentrated precipitate $(\approx 10 \mathrm{wt} . \%)$, washed precipitate $(\approx 10 \mathrm{wt} . \%)$, and filtrate from concentration and washing were analyzed for B2SS. All samples were analyzed by gel permeation reverse-phased high-performance liquid chromatography (HPLC) equipped with an evaporative light scattering detector. The samples were prepared by liquid-liquid extraction with tetrahydrofuran. All sample extractions took place within the same shift that the samples were taken from the process. The low salt samples (washed precipitate and permeate from washing) were neutralized with $1 \mathrm{M} \mathrm{HNO}_{3}$ and analyzed by HPLC. A blank sample containing a known amount of IIT B52 antifoam was also submitted for analysis. The blank sample that was submitted was an aliquot from the diluted Batch 2 antifoam solution (1:100 water) used during the experiment. The diluted Batch 3 antifoam was also submitted for analysis. The sample results are presented in Table 5. Sample analysis shows that the active ingredient in IIT B52 was consumed during the experiment. Additionally, the sample results for the Batch 3 antifoam shows that the active ingredient is completely soluble in the ethanol phase. The slightly higher than expected analytical result for the Batch 3 antifoam is likely due to evaporation of ethanol prior to analysis.

Table 5 - IIT B52 Sample Analysis from Precipitation, Filtration and Washing

\begin{tabular}{|c|c|c|c|c|}
\hline \multirow[b]{2}{*}{ Sample Type (Insoluble Solids Loading) } & & \multicolumn{3}{|c|}{$\begin{array}{c}\text { IIT B52 ANTIFOAM ACTIVE } \\
\text { INGREDIENT CONCENTRATION } \\
\text { Bis(2-ethylhexyl)sodium } \\
\text { sulfosuccinate; (B2SS) }\end{array}$} \\
\hline & & $\begin{array}{c}\text { Measured, } \\
\mathrm{mg} / \mathrm{L}\end{array}$ & \begin{tabular}{|c|} 
Expected, \\
$\mathrm{mg} / \mathrm{L}$
\end{tabular} & $\begin{array}{l}\% \\
\text { Difference }\end{array}$ \\
\hline Dilute Precipitate (0.6 wt. \%) & | $<$ & 23 & 75 & $-106.1 \%$ \\
\hline Concentrated Precipitate (10 wt. \%) & 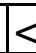 & 23 & 75 & $-106.1 \%$ \\
\hline Washed Precipitate (10 wt. \%) & 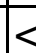 & 15 & 75 & $-133.3 \%$ \\
\hline Filtrate From Concentration & 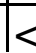 & 15 & 75 & $-133.3 \%$ \\
\hline Filtrate From Washing & 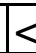 & 15 & 75 & $-133.3 \%$ \\
\hline $\begin{array}{l}\text { Water Blank spiked with IIT B52 Batch } 2 \text { (75\% } \\
\text { Active) }\end{array}$ & & 7700 & 7500 & $2.6 \%$ \\
\hline $\begin{array}{l}\text { Diluted Antifoam Solution Batch } 3 \text { (70\% } \\
\text { active) in Ethanol 7.4:1 }\end{array}$ & & 78200 & 70907 & $9.8 \%$ \\
\hline
\end{tabular}


The total amount of antifoam used during the run is reported in Table 6.

Table 6 - Total antifoam used during the Precipitation, Concentration and Washing of Simulated Precipitate Slurry

\begin{tabular}{|lrrrr|}
\hline & $\begin{array}{l}\text { Batch 3, Total } \\
\text { Antifoam Used, g }\end{array}$ & \multicolumn{2}{c}{$\begin{array}{l}\text { Batch 2, Total } \\
\text { Antifoam Used, g }\end{array}$} & Total \\
\hline Precipitation & 12.0 & 16.1 & 28.1 \\
\hline Concentration \& Washing & 11.3 & 17.3 & 28.6 \\
\hline Total by Type & 23.3 & 33.4 \\
\hline
\end{tabular}

B2SS is a wetting agent that has been used in textile, pharmaceutical, cosmetic and food applications ${ }^{17}$. The wetting properties of B2SS and other sodium sulfosuccinic esters have been characterized for many years ${ }^{18}$. B2SS and other organic sulfonate compounds have been patented as antifoam agents in non-aqueous systems ${ }^{19}$. B2SS, in combination with other organic chemicals, has also been used to control foaming in pulp and papermaking aqueous systems $^{20}$. B2SS is known to hydrolyzed under basic conditions (saponification) ${ }^{21}$. B2SS is sold by the BASF Corporation in a dilute water solution under the trade name Leophen ${ }^{\circledR}$ RA. The stability of Leophen ${ }^{\circledR} \mathrm{RA}$ at various temperatures and $\mathrm{pH}$ conditions is shown in Table $7^{22}$. The data clearly shows that B2SS rapidly hydrolyzed in high $\mathrm{pH}$ or temperature conditions.

Table 7 - Stability of Leophen ${ }^{(\mathbb{R} A}$ RA (Bis(2-ethylhexyl)sodium sulfosuccinate) at Various pH and Temperature Conditions

\begin{tabular}{|lll|}
\hline $\boldsymbol{p H}$ & Temperature $(\boldsymbol{C})$ & $\mathbf{\%}$ Hydrolyzed \\
\hline $\begin{array}{l}\mathbf{p H} \mathbf{2 . 4}- \\
\mathbf{8}\end{array}$ & 100 & $0 \%$ after 4 hours \\
\hline $\mathbf{1 0}-\mathbf{1 2}$ & 50 & $12 \%$ after $2 \mathrm{hr}$ \\
\hline $\mathbf{1 0}-\mathbf{1 2}$ & 70 & $20 \%$ after $1 \mathrm{hr}$ \\
\hline $\mathbf{1 0}-\mathbf{1 2}$ & 70 & $50 \%$ after $1 \mathrm{hr} 20 \mathrm{~min}$. \\
\hline $\mathbf{1 0}-\mathbf{1 2}$ & 100 & $50 \%$ after $8 \mathrm{~min}$. \\
\hline $\mathbf{1 4}$ & 30 & $50 \%$ after $30 \mathrm{~min}$. \\
\hline $\mathbf{1 4}$ & 50 & $50 \%$ after $14 \mathrm{~min}$. \\
\hline $\mathbf{1 4}$ & 70 & $50 \%$ after $3 \mathrm{~min}$. \\
\hline
\end{tabular}

17 The Merck Index, $12^{\text {th }}$ Edition on CD -ROM Version 12:1, Chapman \& Hall, 1996. Entry 3460 Docusate Sodium

18 C. R. Caryl, "Sulfosuccinic Esters”, Ind. Eng. Chem., Vol. 33 p. 731-737, June 1941

${ }^{19}$ U.S. Pat. No. 5,169,560, "Control of Foam in Hydrocarbon Fluids", P. R. Hart, 9/17/1990.

${ }^{20}$ U.S. Pat. No. 3,751,373, Lieberman et al., August 1973.

${ }^{21}$ H. Popovici and A. Chiriac, "The Effect of Sodium Sulphate upon Bis(2-EthylHexyl)

Sulphosuccinate Sodium Salt Alkaline Hydrolysis", Annals of Western University of Timisoara ,Vol. 4 pp. 17-21, 1995

${ }^{22}$ Technical Bulletin TI/T 7004, “Technical Information for Leophen ${ }^{\circledR}$ RA” BASF

Corporation, September 1998. 
One form of the hydrolysis reaction is shown in Figure 13. The reaction products are sodium sulfosuccinate and 2-ethyl-1-hexanol (2-Ethylhexanol). The alcohol is known to have some antifoaming properties ${ }^{23,24}$. The solubility of 2-ethylhexanol in water is reported by Merck to be approximately $1387 \mathrm{ppm}$ (Soluble in $\approx 720$ parts water). The solubility of B2SS is approximately $15 \mathrm{~g} / \mathrm{L}$. The solubility of sodium sulfosuccinate in water was not readily available from the literature. However given the polar structure of sodium sulfosuccinate, the solubility is probably at least as great as 2-ethylhexanol. Therefore, some of the reaction products are probably removed from the precipitate slurry during the concentration and washing cycle.
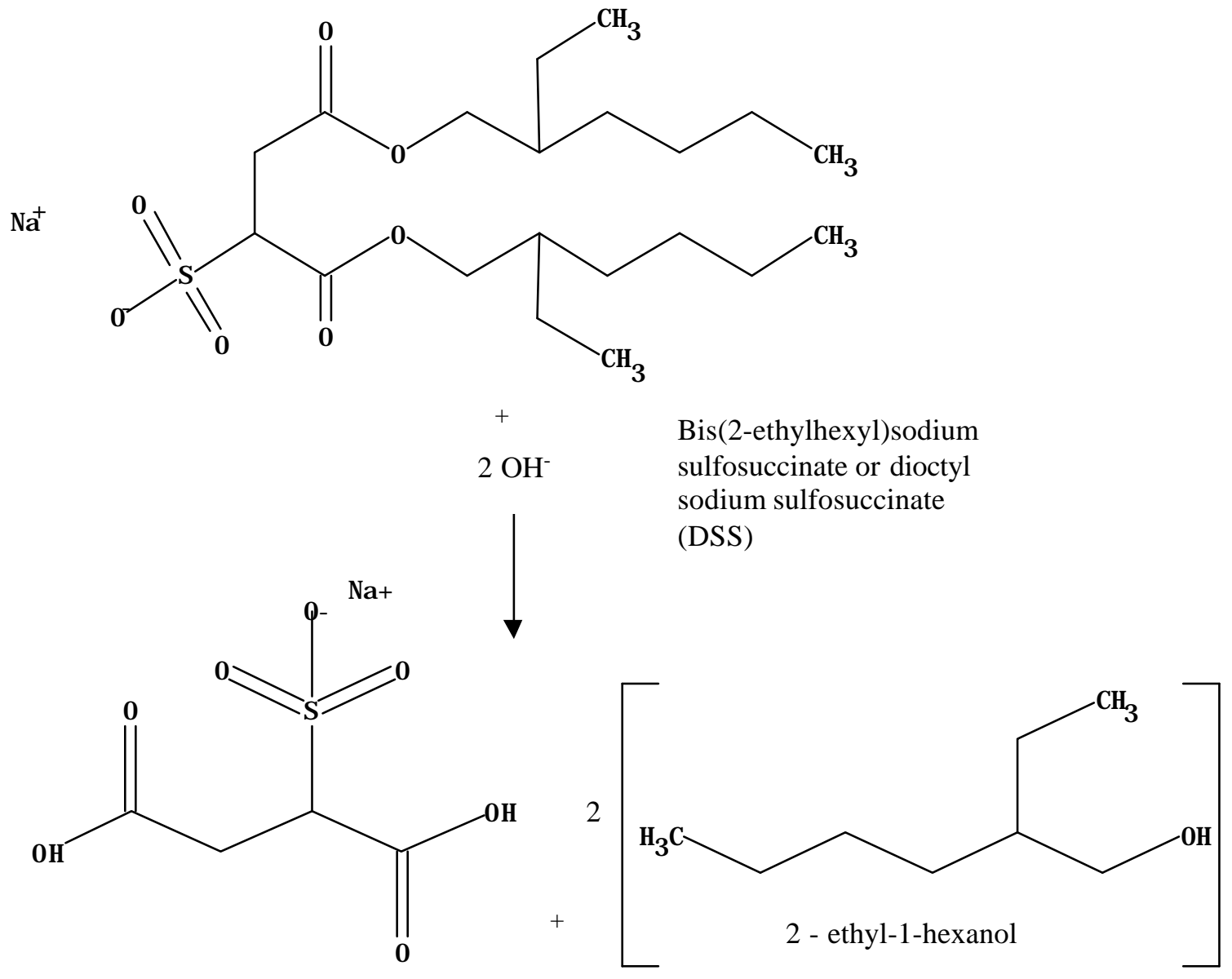

Sodium

sulfosuccinate

Figure 13 - Hydrolysis of IIT B52 (B2SS, Bis(2-ethylhexyl)sodium sulfosuccinate)

${ }^{23}$ The Merck Index, $12^{\text {th }}$ Edition on CD -ROM Version 12:1, Chapman \& Hall, 1996. Entry 3854.

${ }^{24}$ R. Defago (Ciba-Geigy A.-G., Switz.), European Patent No. 210130, "Blank Paste and its use Printing Pastes for the Printing of Transfer Sheets Used in Transfer Printing”, 1987 
Samples of washed precipitate slurry and filtrate containing antifoam were submitted for 2etylhexanol analyses using gas chromatography/mass spectrometer (GC/MS). Analytical separations were carried out on a Hewlett Packard 6890 gas chromatograph, equipped with a 30 m DB-5 column. Quantification was preformed using a Hewlett Packard 5973 mass selective detector. The mass spectrometer tuning was confirmed within 24 hours prior to each measurement using perfluorotributylamine. Results are shown in Table 8. The results confirm the presence of 2-ethylhexanol as indicated by the literature. Analytical data indicates that the hydrolysis products are not concentrated in the Concentrate Tank and are removed via the filtrate during washing cycle.

IIT B52 was added at an average concentration of $150 \mathrm{ppmV}$ (See section 4.1.2). Given the reaction shown in Figure 13, the calculated concentration of 2-ethylhexanol should have been approximately $88 \mathrm{ppmV}$ as compared to the measured value of $120 \mathrm{ppmV}$ (31\% difference). The measured value is considered to be in good agreement with the predicted. Therefore, given the literature and analytical results, B2SS will hydrolyze in the STTP process to form 2ethylhexanol and sodium sulfosuccinate.

Table 8 - 2-Ethyl-1-Hexanol (IIT B52 Hydrolysis Product) Analysis of Washed KTPB Slurry and Filtrate from Washing

\begin{tabular}{|l|c|c|}
\hline Sample & $\begin{array}{c}\text { 2-ethyl-1-hexanol, } \\
\mathrm{mg} / \mathrm{L}\end{array}$ & $\begin{array}{c}\text { Detection } \\
\text { Limit, mg/L }\end{array}$ \\
\hline $\begin{array}{l}11.3 \text { wt. \% Washed KTPB Slurry with } \\
\text { Antifoam }\end{array}$ & 120 & 10 \\
\hline Filtrate from Washing & 18 & 10 \\
\hline
\end{tabular}

Selected properties for 2-Ethyl-1-Hexanol are shown in Table 9.

Table 9 - Selected Properties of 2-Ethyl-1-Hexanol

\begin{tabular}{lc} 
Property & 2-Ethyl-1-Hexanol \\
\hline Boiling Point at 760 mmHg, C & 185 \\
Flashpoint, C & 82 \\
Vapor Pressure @ 20 C, mmHg & 0.05 \\
Specific Gravity @ 20 C & 0.834 \\
Upper Flammability Limit \% by vol. & 5.7 \\
Lower Flammability Limit \% by vol. & 0.9 \\
\hline
\end{tabular}

\subsubsection{Insoluble Aluminum Analysis and Results}

Samples were taken during precipitation, concentration and washing to determine if insoluble aluminum would form during processing. Slurry samples were dissolved using an aqua regia acid preparation and analyzed by ICP-ES for Al. Additional slurry samples were filtered to remove any insoluble aluminum. The resulting filtrate samples were diluted and analyzed by 
ICP-ES. Permeate samples were diluted and analyzed for total aluminum. Permeate samples were also filtered, diluted and analyzed by ICP-ES for Al.

The slurry and unfiltered permeate sample analysis (Total Aluminum) was subtracted from the filtrate derived from filtering the slurry and permeate samples (Soluble Aluminum) to obtain the Insoluble Aluminum concentration. Duplicate samples were submitted.

Table 10 shows a summary of the aluminum analysis for the antifoam run. No insoluble aluminum formed during the precipitation and concentration cycles. The total and soluble aluminum values reported for the 0.6 and $10 \mathrm{wt}$. \% slurry and the filtrate from concentration and washing are well within expected analytical error $(\approx 10 \%)$ for $\mathrm{Al}$ analysis by ICP-ES. Insoluble aluminum was added as Purex sludge. The Purex sludge solids contained approximately $3.83 \mathrm{wt}$ \% Al. Approximately, $19.8 \mathrm{~g}$ of Purex sludge solids was added per 50 $\mathrm{L}$ of precipitate slurry. Therefore, the concentration of $\mathrm{Al}$ in the precipitate slurry resulting from the sludge was calculated to be $15 \mathrm{mg} / \mathrm{L}$. The calculated insoluble $\mathrm{Al}$ resulting from sludge after concentrating the precipitate slurry to $10 \mathrm{wt}$. $\%$ was $213 \mathrm{mg} / \mathrm{L}$. The predicted Al concentration (total, soluble and insoluble $\mathrm{Al}$ ) for 0.6 and $10 \mathrm{wt}$. \% slurries is presented in Table 10.

The total and soluble $\mathrm{Al}$ analyses for the $10 \mathrm{wt} . \%$ slurry are lower $(\approx 12 \%$ difference) than the 0.6 wt. \% slurry analysis. This difference is likely due to segregation of the solids during sampling and random laboratory error.

Analytical results for the washed precipitate indicate that insoluble aluminum formed during the experiment. A sample of washed precipitate was filtered and the solids were submitted for analysis by x-ray diffraction. The presence of Gibbsite $\left(\mathrm{Al}(\mathrm{OH})_{3}\right)$ was confirmed in the XRD analysis shown in Figure 14. The concentration of insoluble aluminum formed during the experiment is approximately $940 \mathrm{mg} / \mathrm{L}$ assuming that all the Al from the sludge remain insoluble during the experiment.

Reference ${ }^{25}$ indicates that the solubility of $\mathrm{Al}$ in water at $\mathrm{pH} 12$ ( 0.01 hydroxide) is approximately $222 \mathrm{mg} / \mathrm{L}$. Since the starting Al concentration was well above the reported solubility limit, it is possible that near the addition point of the inhibited water, temporary reductions in the hydroxide concentration could have caused Gibbsite to precipitate during the experiment. Low laboratory temperature ( $\approx 17 \mathrm{C}$ ) which occurred during the experiment could also have decreased the solubility of $\mathrm{Al}$ in the precipitate slurry. Reference ${ }^{25}$ indicates that solutions saturated with gibbsite approach equilibrium very slowly (several days to weeks). Therefore, the gibbsite formed during the experiment may not have had the time to dissolve during the washing cycle (2 days). At the completion of the washing cycle, the hydroxide concentration was not high enough to allow the insoluble $\mathrm{Al}$ to dissolve.

${ }^{25}$ C. H. Baes, Jr. \& R. E. Mesmer, “The Hydrolysis of Cations”, John Wiley \& Sons, Inc. 1976

Page 30 of 34 
Table 10 - Summary of Aluminum Sample Analysis - Total, Soluble and Insoluble Al

\begin{tabular}{|c|c|c|c|c|c|}
\hline SAMPLE & $\begin{array}{l}\text { TOTAL AL, } \\
\text { MG/L }\end{array}$ & $\begin{array}{l}\text { SOLUBLE AL, } \\
\text { MG/L }\end{array}$ & $\begin{array}{c}\% \\
\text { DIFFERENCE }\end{array}$ & $<$ & $\begin{array}{l}\text { INSOLUBLE } \\
\text { AL, MG/L }\end{array}$ \\
\hline $\begin{array}{l}\text { 0.6 wt. \% Precipitate } \\
\text { Slurry (Predicted) }\end{array}$ & 7910 & 7894 & & & 15 \\
\hline $\begin{array}{l}0.6 \text { wt. \% Precipitate } \\
\text { Slurry (Measured) }\end{array}$ & 8831 & 8943 & $-1.3 \%$ & & 0 \\
\hline $\begin{array}{l}\% \text { Difference (Predicted } \\
\text { vs. Measured) }\end{array}$ & $11.0 \%$ & $12.4 \%$ & & & \\
\hline $\begin{array}{l}10 \text { wt. \% Precipitate } \\
\text { Slurry (Predicted) }\end{array}$ & 8108 & 7895 & & & 213 \\
\hline $\begin{array}{l}10 \text { wt. \% Precipitate } \\
\text { Slurry (Measured) }\end{array}$ & 7895 & 8285 & $-4.8 \%$ & & $\overline{0}$ \\
\hline $\begin{array}{l}\text { \% Difference (Predicted } \\
\text { vs. Measured) }\end{array}$ & $\mid-2.7 \%$ & $4.8 \%$ & & & \\
\hline $\begin{array}{l}\text { Filtrate from } \\
\text { Concentration } \\
\text { (Measured) }\end{array}$ & 8360 & 8660 & $-3.5 \%$ & & 0 \\
\hline $\begin{array}{l}10 \text { wt. \% Washed } \\
\text { Precipitate Slurry } \\
\text { (Measured) }\end{array}$ & 1282 & 126 & $164.2 \%$ & & 1156 \\
\hline $\begin{array}{l}10 \text { wt. \% Washed } \\
\text { Precipitate Slurry (Not } \\
\text { Including Sludge Solids) }\end{array}$ & & & & & 943 \\
\hline $\begin{array}{l}\text { Filtrate from Washing } \\
\text { (Measured) }\end{array}$ & 142 & 149 & $-4.8 \%$ & & 0 \\
\hline
\end{tabular}

Table 11 provides an analysis of the insoluble aluminum from an overall material balance perspective. The insoluble Al concentration and the total quantity of dilute precipitate and washed precipitate are used to calculate the percent insoluble aluminum in the salt solution that precipitated during the washing cycle. Less than $1 \%$ of the Total aluminum fed to the process precipitated in the washing cycle. The insoluble aluminum composes less than $1 \%$ of the total mass of washed insoluble solids produced. Since the STTP process is designed to handle solids, the small quantity of Al that precipitated during the experiment should not have a significant effect on the overall process. 
Table 11 - Percent of Insoluble Al in the Feed that Precipitated during the Washing Cycle

\begin{tabular}{|c|c|c|}
\hline & $\begin{array}{l}\text { Salt } \\
\text { Solution }\end{array}$ & $\begin{array}{l}10 \text { wt. \% } \\
\text { Washed } \\
\text { Precipitate }\end{array}$ \\
\hline Total Al, mg/L & 7910 & 1156 \\
\hline Total Insoluble Al, mg/L & 15 & 943 \\
\hline Total , L & 220 & 12 \\
\hline $\begin{array}{l}\% \text { of Total Al in the Feed that Precipitated during } \\
\text { Washing Cycle }\end{array}$ & & $0.7 \%$ \\
\hline \% Insoluble Solids & $0.6 \%$ & $10 \%$ \\
\hline Density, $\mathrm{g} / \mathrm{ml}$ & 1.19 & 1.03 \\
\hline $\begin{array}{l}\text { \% of Insoluble Al in the Washed Precipitate Solids } \\
\text { due to AI Precipitation in the Washing Cycle }\end{array}$ & - & $0.9 \%$ \\
\hline $\begin{array}{l}\text { \% of Insoluble Al in the Washed Precipitate Solids } \\
\text { due to Sludge }\end{array}$ & - & $0.2 \%$ \\
\hline
\end{tabular}

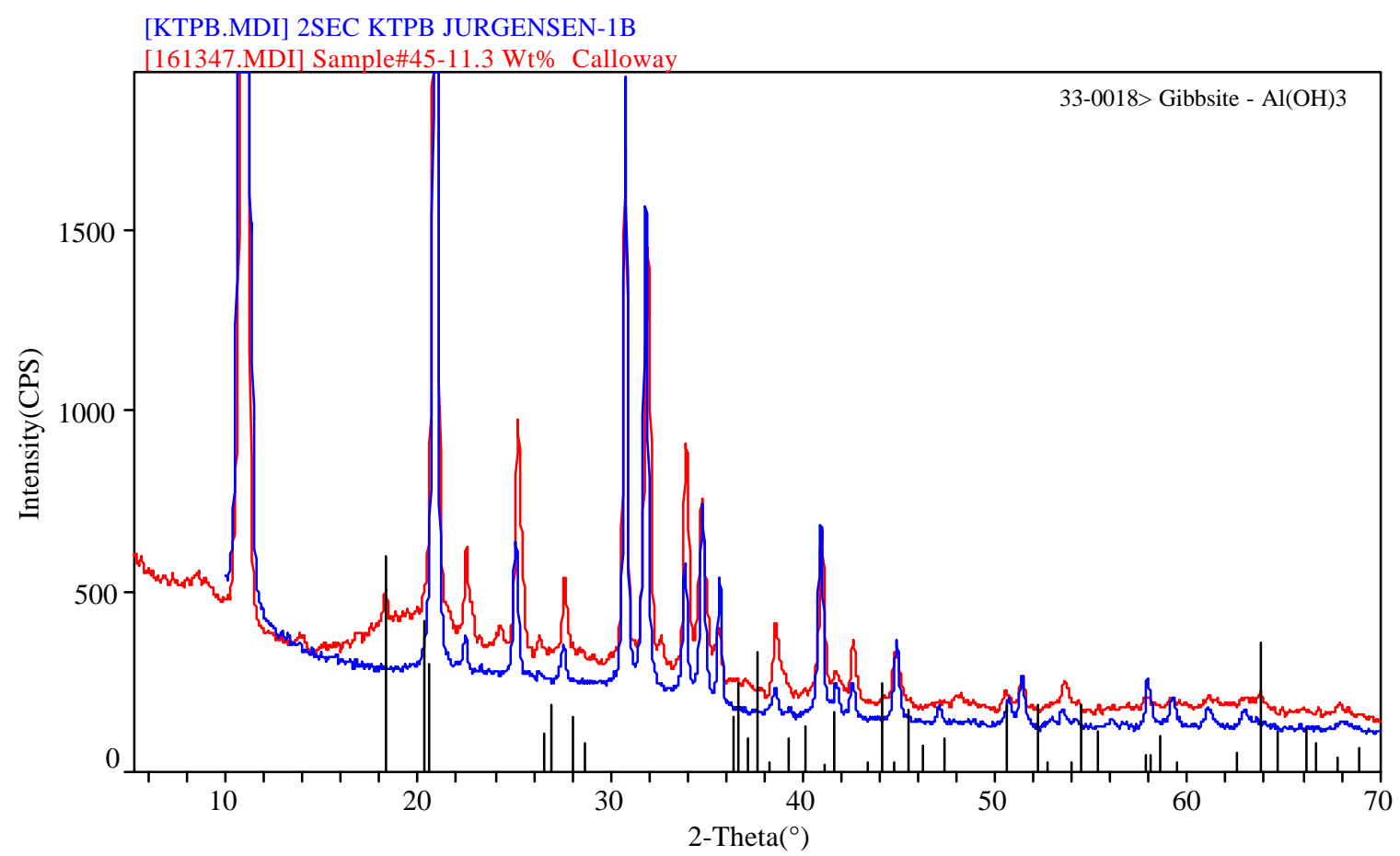

Figure 14 - XRD Analysis of Insoluble solids in Washed Concentrated Precipitate Slurry 


\subsection{CONCLUSIONS}

The IIT B52 antifoam agent was tested on a laboratory scale with simulated KTPB slurry using the proposed STTP process precipitation, concentration and washing steps. This test was compared to an identical test conducted with antifoam and simulated KTPB slurry.

Even under extreme agitation, foaming did not occur in precipitate slurries produced with or without antifoam during the precipitation cycle. Foaming did not occur in the concentration and washing cycles conducted with antifoam. The formation of KTPB foam is not a recoverable event without the use antifoam. If gas entrainment in the slurry is carefully avoided little or no foam will be generated during normal operations during concentration and washing of the precipitate. Ultimately, the STTP process should be designed to minimize the introduction of gas into the slurry during concentration and washing. However, gas can become entrained in the process via several mechanisms: 1) during startup and initial filling of the system, 2) by uncovering the agitator blades, 3) through use of pneumatic level/density instrumentation, or 4) by entrainment of gas at the surface of the liquid during agitation. Therefore, antifoam will be required during concentration and washing.

All of the IIT B52 antifoam was consumed during the precipitation, concentration and washing cycles. No amount of the active antifoam ingredient (bis(2-ethylhexyl)sodium sulfosuccinate) was detected in the dilute precipitate $(0.6 \mathrm{wt} . \%)$, concentrated precipitate (10 wt. \%), washed precipitate (10 wt. \%), or the permeate from concentration and washing. A brief literature search revealed that bis(2-ethylhexyl)sodium sulfosuccinate undergoes hydrolysis in strong basic conditions (saponification) to form sodium sulfosuccinate and 2ethyl-1-hexanol. Both bis(2-ethylhexyl) sodium sulfosuccinate and 2-ethyl-1-hexanol have been used as antifoam agents in other industrial applications. Analytical results confirmed the presence of 2-ethyl-1-hexanol in the washed precipitate and in the filtrate collected during washing. IIT B52 was added at an average concentration of $150 \mathrm{ppmV}$. Given the reaction shown in Figure 13, the calculated concentration of 2-ethylhexanol should have been approximately $88 \mathrm{ppmV}$ as compared to the measured value of $120 \mathrm{ppmV}$ ( $31 \%$ difference). The measured value is considered to be in good agreement with the predicted value. The analytical data indicates that the hydrolysis products are not concentrated during the concentration cycle and are at least partially removed from the slurry during filtration. Therefore, given the literature and analytical results, B2SS will hydrolyze in the STTP process to form 2-ethylhexanol and sodium sulfosuccinate. The hydrolysis reaction products are partially soluble in water and are expected to be present in the precipitate slurry and the filtrate.

Insoluble aluminum formed during the washing cycle. Gibbsite was present in washed precipitate slurry at concentrations in excess of $940 \mathrm{mg} / \mathrm{L}$. Less than $1 \%$ of the total aluminum fed to the process precipitated in the washing cycle. The insoluble aluminum in the washed precipitate composes less than $1 \%$ of the total mass of insoluble solids produced. Since the STTP process is designed to handle solids, the small quantity of Al that precipitated during the experiment should not have a significant effect on the overall process. 
The IIT B52 antifoam affects the settling characteristics of the precipitate slurries. The insoluble solids in slurries produced without antifoam floated at the surface, whereas the concentrated slurries produced with antifoam settled to the bottom of the test vessels and storage containers. Based upon this testing, as little as $100 \mathrm{ppmV}$ of IIT B52 causes a significant change in the slurry settling characteristics.

\subsection{FUTURE WORK}

This study did not investigate the optimal concentration of antifoam necessary to effectively mitigate foaming in the concentration and washing steps. The degradation kinetics and solubility of IIT B52 antifoam and reaction products in a high caustic environment needs to be investigated. Additionally, the antifoaming properties of the IIT B52 hydrolysis products should also be investigated. The concentration of antifoam versus the change in the slurry physical properties requires further study. Due to the observed decrease in washing efficiency with antifoam, a more detailed study of the washing effectiveness as a function of antifoam concentration is warranted. Furthermore, a simplified foaming test (e.g. agitated beaker) versus the current foam column test needs to be devised and standardized for future testing. The foam column tests are not realistic as compared to actual plant conditions and may provide an overly conservative indication of the foaminess of the KTPB slurries. A simplified test similar to those encountered in the plant would provide a more realistic test and, if designed correctly, would reduce the cost of future antifoam studies conducted for the STTP process.

\subsection{REFERENCES}

See footnotes

\section{ACKNOWLEDGEMENTS}

This work could not have been completed without the analytical support provided by Tom White, David Best, Steve Crump, Eric Frickey and Art Jurgenson. These individuals and their supporting organizations contributed to the success of this project. 


\section{DISTRIBUTION:}

M. J. Barnes, 773

S. B. Beck, 704-1N

P. C. Suggs, $704-196 \mathrm{~N}$

J. T. Carter, 704-3N

N. F. Chapman, 210-S

G. A. Taylor, 704-196N

Paul Taylor, ORNL

Jack Collins, ORNL

W. L. Tamosaitis, 773-A

H. H. Elder, 704-196N

W. B. Van Pelt, 773-42A

S. D. Fink, 773-A

F. F. Fondeur, 773-A

D. D. Walker, 773-A

J. R. Fowler, 704-196N

Joe Walker, ORNL

Dennis Wester, PNNL

T. Hang, 773-43A

T. L. White, 773-A

D. C. Hannah, 703-46A

W. R. Wilmarth, 773-42A

H. D. Harmon, 704-3N

J. E. Young, 773-A

R. N. Hinds, 704-3N

D. T. Hobbs, 773-A

E. W. Holtzscheiter, 773-A

STI, 703-43A (4 copies)

LWP Files, c/o Cathy Canada, 773-A

W. M. Howell, 704-196N

ITP Files, c/o Cathy Smalls, 241-147H

R. A. Jacobs, 704-3N

R. T. Jones, 704-3N

Tim Kent, ORNL

Leon Klatt, ORNL

D. P. Lambert, 704-1T

T. B. Calloway, 704-1T

M. A. Baich, 786-1A

B. L. Lewis, 703-H

T. J. Lex, 703-H

C. J. Martino, 773-A

J. W. McCullough, 704-3N

J. P. Morin, 703-H

B. A. Moyer, ORNL

L. M. Nelson, 773-43A

L. N. Oji, 773-43A

L. M. Papouchado, 773-A

T. B. Peters, 773-24A

S. F. Piccolo, 703-H

J. A. Pike, 704-196N

M. R. Poirier, 773-42A

L. D. Prince, 773-41A

J. Reynolds, 704-S

S. N. Schlahta, 704-3N

F. G. Smith, 773-42A

S. G. Subosits, 704-196N

R. H. Spires, 773-A

D. A. Crowley, 773-43A

W. E. Stevens, 773-A 